\title{
Muscle biopsy essential diagnostic advice for pathologists
}

\author{
Ana Cotta ${ }^{1 *} \mathbb{D}$, Elmano Carvalho², Antonio Lopes da-Cunha-Júnior ${ }^{3}$, Jaquelin Valicek ${ }^{2}$, Monica M. Navarro ${ }^{4}$, \\ Sidney Baptista Junior ${ }^{1}$, Eni Braga da Silveira ${ }^{5}$, Maria Isabel Lima ${ }^{5}$, Bruno Arrivabene Cordeiro ${ }^{5}$, \\ Alexandre Faleiros Cauhi ${ }^{6}$, Miriam Melo Menezes ${ }^{7}$, Simone Vilela Nunes ${ }^{7}$, Antonio Pedro Vargas ${ }^{7}$, \\ Rafael Xavier Neto ${ }^{7}$ and Julia Filardi Paim ${ }^{1}$
}

\begin{abstract}
Background: Muscle biopsies are important diagnostic procedures in neuromuscular practice. Recent advances in genetic analysis have profoundly modified Myopathology diagnosis.

Main body: The main goals of this review are: (1) to describe muscle biopsy techniques for non specialists; (2) to provide practical information for the team involved in the diagnosis of muscle diseases; (3) to report fundamental rules for muscle biopsy site choice and adequacy; (4) to highlight the importance of liquid nitrogen in diagnostic workup. Routine techniques include: (1) histochemical stains and reactions; (2) immunohistochemistry and immunofluorescence; (3) electron microscopy; (4) mitochondrial respiratory chain enzymatic studies; and (5) molecular studies. The diagnosis of muscle disease is a challenge, as it should integrate data from different techniques.

Conclusion: Formalin-fixed paraffin embedded muscle samples alone almost always lead to inconclusive or unspecific results. Liquid nitrogen frozen muscle sections are imperative for neuromuscular diagnosis. Muscle biopsy interpretation is possible in the context of detailed clinical, neurophysiological, and serum muscle enzymes data. Muscle imaging studies are strongly recommended in the diagnostic workup. Muscle biopsy is useful for the differential diagnosis of immune mediated myopathies, muscular dystrophies, congenital myopathies, and mitochondrial myopathies. Muscle biopsy may confirm the pathogenicity of new gene variants, guide cost-effective molecular studies, and provide phenotypic diagnosis in doubtful cases. For some patients with mitochondrial myopathies, a definite molecular diagnosis may be achieved only if performed in DNA extracted from muscle tissue due to organ specific mutation load.
\end{abstract}

Keywords: Muscle biopsy, Immunohistochemistry, Electron microscopy, Molecular diagnosis, Surgical pathology, Mitochondrial respiratory chain, Inflammatory myopathy, Mitochondrial myopathy, Congenital myopathy, Muscular dystrophy

\section{Background}

Muscle diseases are a subgroup from neuromuscular affections in which the primary pathological process involves the muscle.

This review provides text, tables and figures useful to understand the indications of some ancillary techniques performed for muscle biopsy interpretation in a

\footnotetext{
* Correspondence: ana_cotta@yahoo.com.br

${ }^{1}$ Department of Pathology, The SARAH Network of Rehabilitation Hospitals, Av. Amazonas, 5953 Gameleira, Belo Horizonte, MG 30510-000, Brazil Full list of author information is available at the end of the article
}

reference center. Figures 1, 2, 3, 4, 5 and 6 provide an overall view of muscle biopsy procedures. The Tables provide useful general myology information (Tables 1, 2, $3,4)$, as well as relevant information for routine myology practice (Tables 5, 6, 7, 8), and a rationale for diagnostic investigation (Table 9).

It is beyond the scope of this review to provide detailed information to establish a Muscle Biopsy Reference Laboratory. Such information may be found on specialized articles and myopathology books (Engel and Franzini-Armstrong 2004; Karpati et al. 2010; Dubowitz

(c) The Author(s). 2021 Open Access This article is licensed under a Creative Commons Attribution 4.0 International License, which permits use, sharing, adaptation, distribution and reproduction in any medium or format, as long as you give appropriate credit to the original author(s) and the source, provide a link to the Creative Commons licence, and indicate if changes were made. The images or other third party material in this article are included in the article's Creative Commons licence, unless indicated otherwise in a credit line to the material. If material is not included in the article's Creative Commons licence and your intended use is not permitted by statutory regulation or exceeds the permitted use, you will need to obtain permission directly from the copyright holder. To view a copy of this licence, visit http://creativecommons.org/licenses/by/4.0/. 


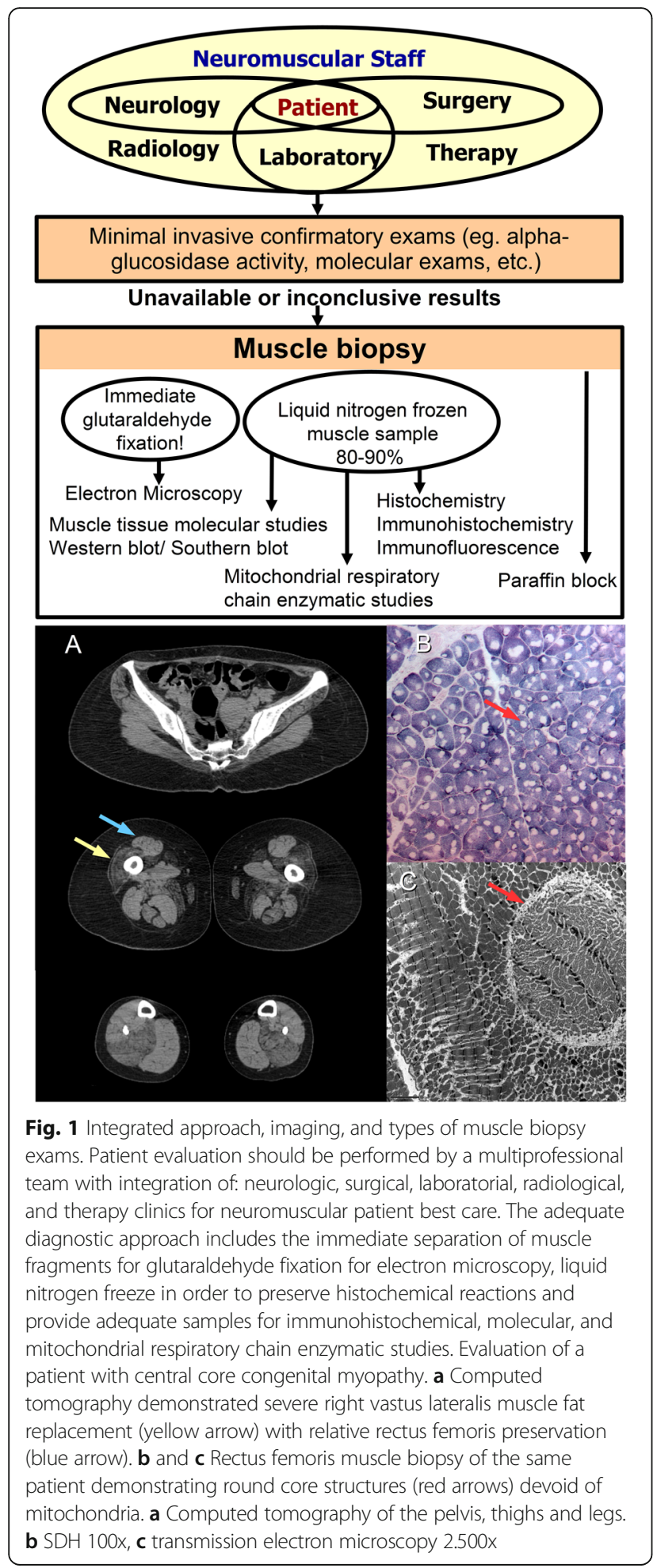

et al. 2020; Dubowitz et al. 2013; Dubowitz and Sewry 2007; Dubowiz 1995; Dubowitz and Brooke 1973; Loughlin 1993; Anderson 1985; Amato and Russell 2008; Levy 1978; Dastgir et al. 2016), historical and contemporary overview of muscle biopsy procedures (Fardeau
2017; Malfatti and Romero 2017; Nix and Moore 2020), didactic internet teaching videos (Table 1) with practical steps for muscle biopsy freezing procedure in accordance to the World Muscle Society standards and protocols (Udd et al. 2019), and special recommendations for patients with malignant hyperthermia (Table 1). It is also beyond the scope of this work, the reproduction of the 39 pages monogenic nuclear genome neuromuscular disorders Gene Table (Benarroch et al. 2019). An updated gene table on nuclear genome neuromuscular disorders is a reference for morphologic-molecular correlation, which is published every year in the journal Neuromuscular Disorders and is freely accessible online (Table 1) (Benarroch et al. 2019).

Some topics of this review were previously presented at the Neuromuscular Diseases Scientific Department Myopathy Course sponsored by the Brazilian Academy of Neurology (ABN: Academia Brasileira de Neurologia).

\section{Does the patient need a muscle biopsy?}

Muscle biopsy is an invasive procedure that should be performed after inconclusive noninvasive methods. Usually, muscle biopsies are useful for patients with: (1) objective muscle weakness, that is detectable through physical examination, (2) increased muscle enzyme levels (serum total creatine kinase and aldolase), (3) abnormal muscle imaging, or (4) myopathic motor unit action potentials on electromyogram (Amato and Russell 2008).

Muscle biopsy may not be performed in patients with characteristic clinical and neurophysiological pattern, that may be confirmed with molecular exams performed in blood samples, such as dystrophinopathy (65 to $70 \%$ may be diagnosed by molecular detection of deletions or duplications in the dystrophin gene), Steinert's myotonic dystrophy, facioscapulohumeral muscular dystrophy, and spinal muscular atrophy (Karpati et al. 2010; Cotta et al. 2017).

In a previous publication from our group (Cotta et al. 2017), we studied the proportion of neuromuscular patients that reached a final diagnosis either by molecular or by muscle biopsy studies. That 17 years retrospective study, from 1999 to 2016, included 1603 patients that received a final conclusive diagnosis at SARAH Network neuromuscular outpatient clinic (Cotta et al. 2017). Molecular studies were responsible for $48.8 \%$ of the diagnosis, while muscle biopsies disclosed $51.2 \%$ of the diagnosis in 16 neuromuscular diagnostic categories (Cotta et al. 2017).

In the last years, our group has also performed muscle biopsies in some patients previously submitted to molecular studies. For those patients, muscle biopsies have been useful to confirm the pathogenicity of variants of unknown significance (VUS). Some examples have been observed in families with muscular dystrophies. They presented inconclusive molecular studies but undoubtful 

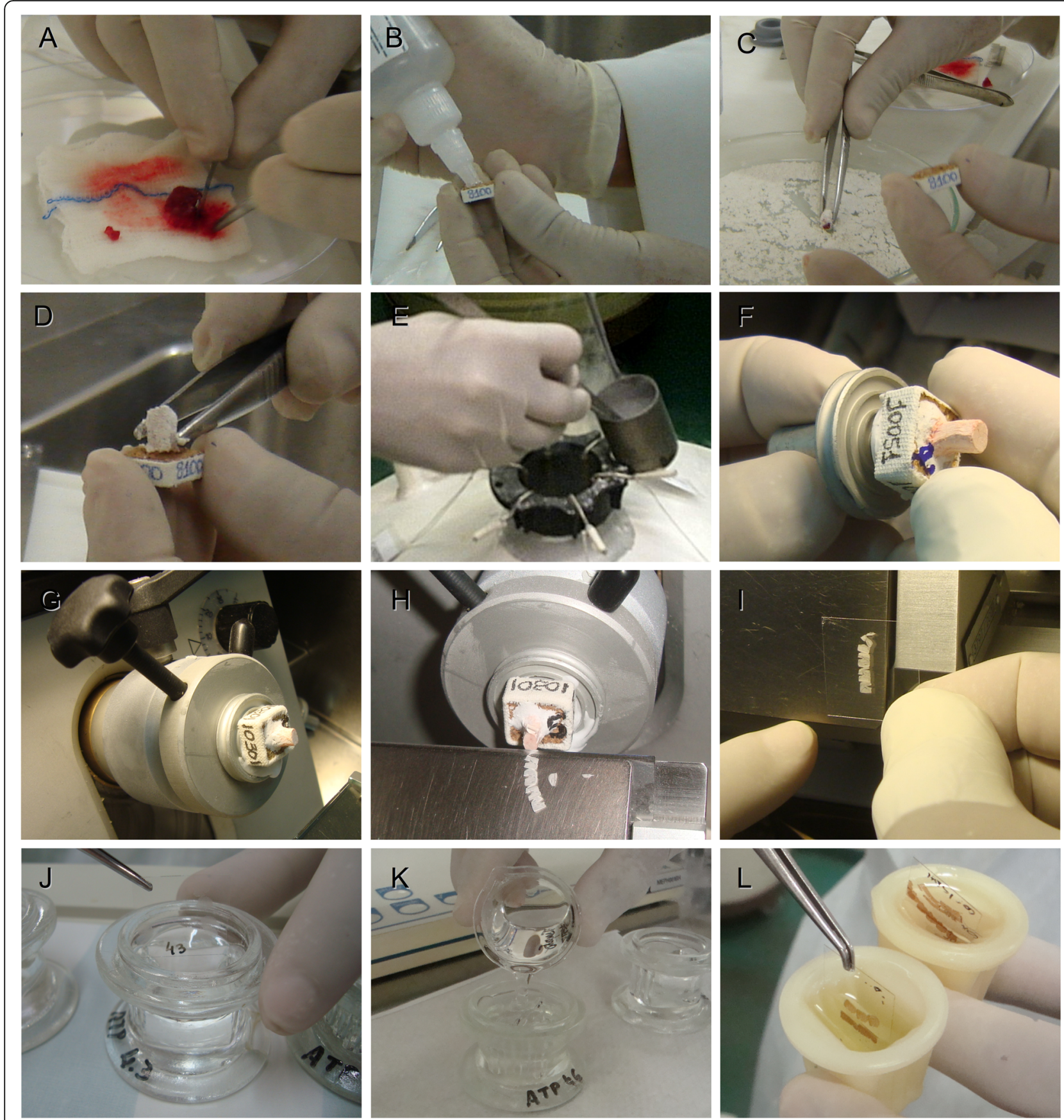

Fig. 2 Muscle preparation for histochemical reactions. a. the fresh muscle sample is sectioned following the longitudinal direction of the fibers and small fragments are immediately glutaraldehyde fixed for eventual electron microscopy studies, if necessary; cylindrical fragments are separated to make liquid nitrogen frozen muscle blocks in order to preserve enzymatic functions. b Optimal cutting temperature (OCT) mounting medium is applied on the surface of the previously identified cork. c The muscle fragment is either cooled in isopentane (data not shown) or involved in talcum powder in order to avoid freezing artifacts. $\mathbf{d}$ Muscle fragment over cork support. e Liquid nitrogen frozen muscle tissue. $\mathbf{f}$ The muscle fragment was frozen in liquid nitrogen and mounted in a cork and a pin. $\mathbf{g}$ The muscle fragment was fixed inside the cryostat for the performance of the frozen sections. $\mathbf{i}$ The frozen section may be transferred either to a coverslip (photo) or to a glass slide (data not shown). $\mathbf{j}$ Coverslip inside reaction dish. $\mathbf{k}$ Frozen sections in incubator. I the incubated coverslips are extracted from the coverslip jar to mount the slides for microscopic visualization 

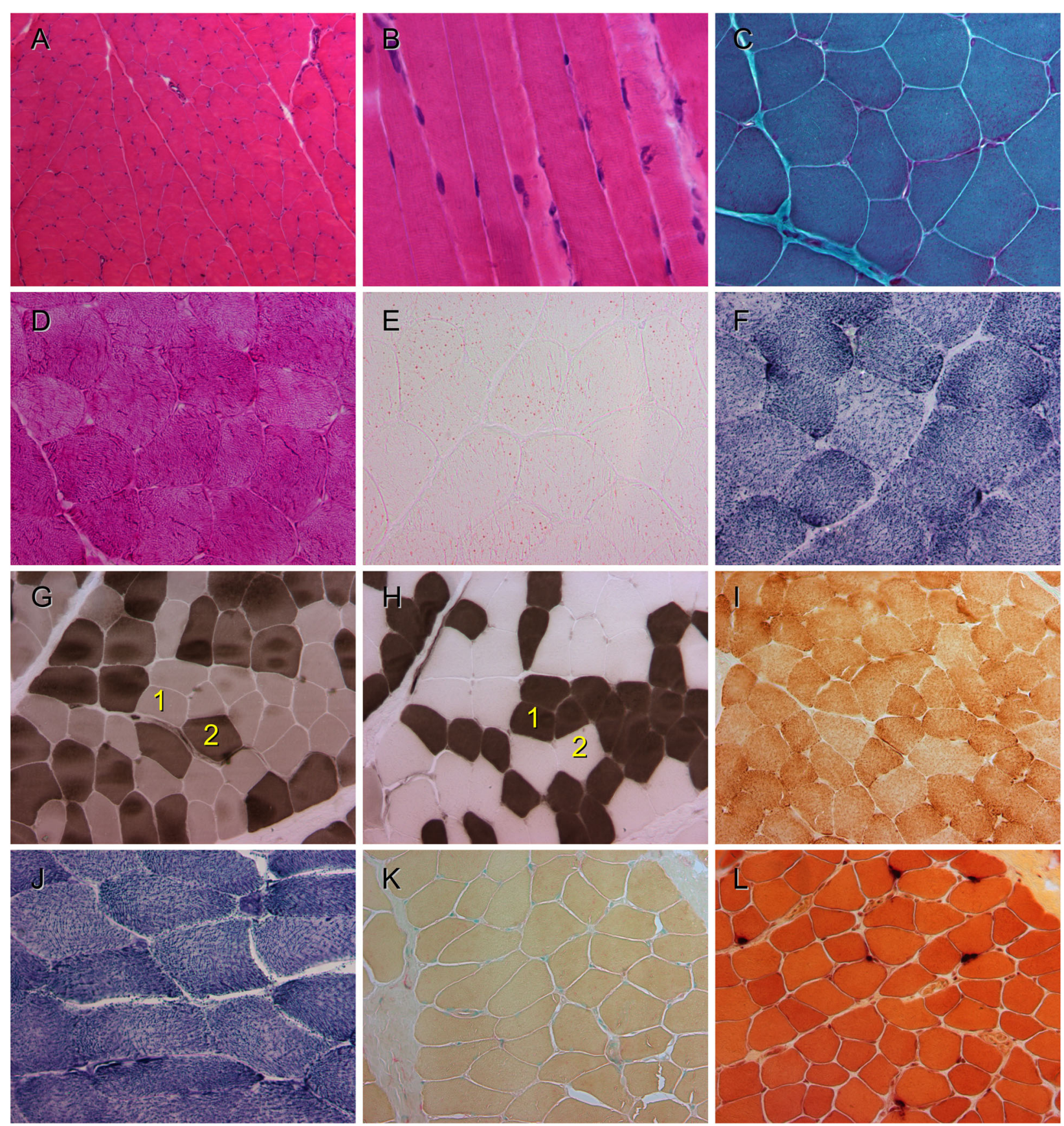

Fig. 3 Normal control muscle histochemical reactions and stains. Muscle obtained from an amputation procedure for orthopedic deformity with normal transverse (a) and longitudinal (b) architecture. Normal mitochondrial (c, $\mathbf{f}$, and $\mathbf{i})$, glycogen (d), and lipid (e) content. No inflammatory activity is observed ( $\mathbf{k}$ and $\mathbf{I}$ ). Normal checkerboard with type 1 (number 1 in $\mathbf{g}$ and $\mathbf{h}$ ) and type 2 (number 2 in $\mathbf{g}$ and $\mathbf{h}$ ) fiber distribution. $\mathbf{I}$ dark dots represent normal neuromuscular junctions (a HE 100x, b HE 400x, c Modified Gomori trichrome 400x, d PAS 400x, e Oil-red-O 400x, f SDH 400x, g ATPase pH 9.4200x, h ATPase pH 4.6200x, i COX 200x, j NADH 400X, k Acid phosphatase 200x, I Nonspecific sterase 200x)

immunohistochemical deficiencies of specific proteins (unpublished data).

\section{How to choose the muscle site for biopsy?}

In an ideal situation, muscle biopsy choice may be part of an integrated multiprofessional approach (Fig. 1).
Muscle selection for biopsy may always consider muscle strength. Whenever possible, the joint evaluation of physical exam and imaging studies should be performed to choose the most superficial muscles (Engel and Franzini-Armstrong 2004; Amato and Russell 2008; Karpati et al. 2010; Dubowitz et al. 2013). 

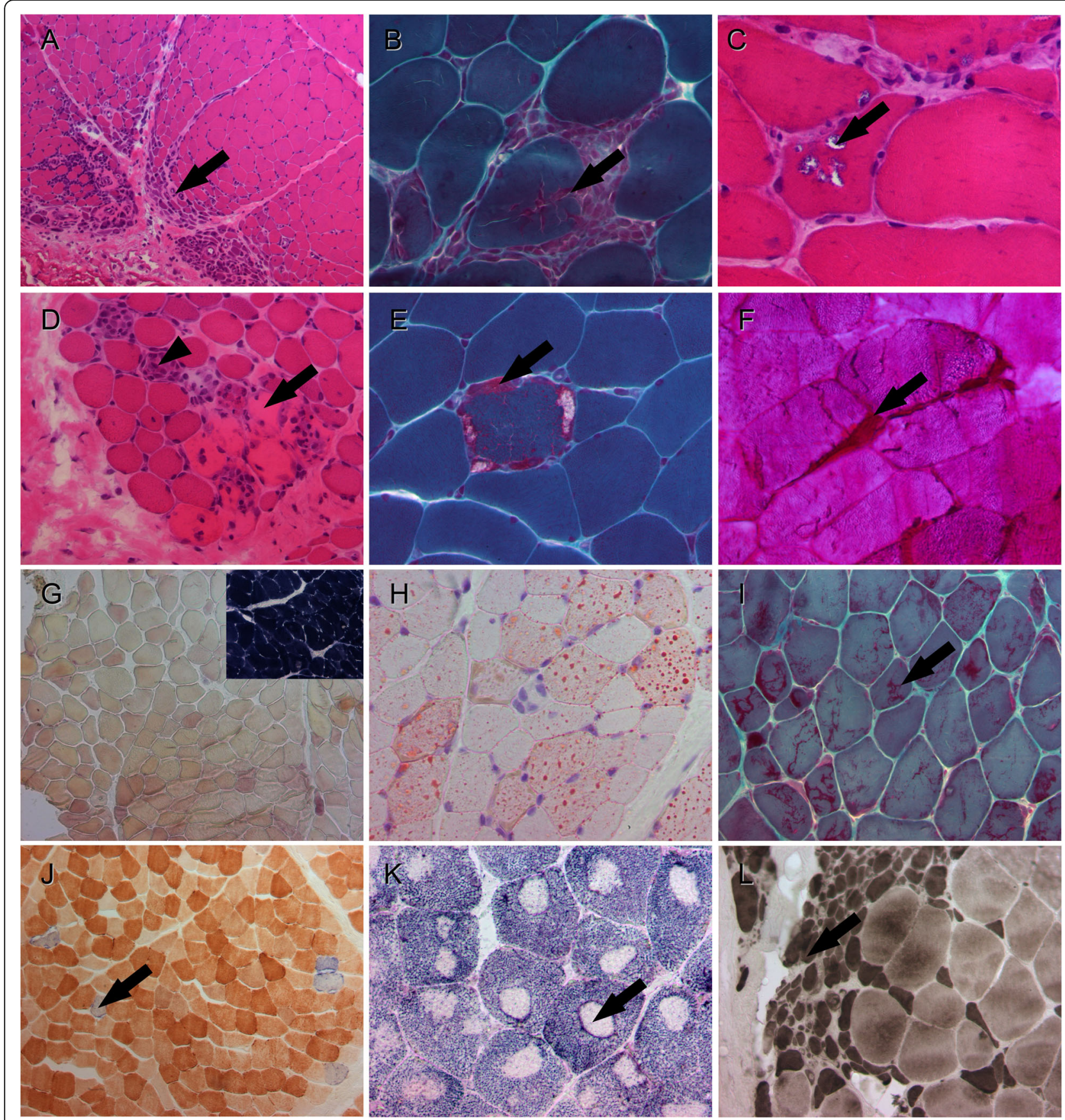

Fig. 4 Morphological findings and histochemical reactions. a Perifascicular atrophy (arrow), ie, peripheral fibers with smaller diameter in patient with dermatomyositis. b Lymphocytic inflammatory infiltrate involving non-necrotic muscle fiber patient with sporadic inclusion body myositis. $\mathbf{c}$ Rimmed vacuole (arrow) in patient with inclusion body myositis associated with HTLV-1 infection. $\mathbf{d}$ Necrosis (eosinophilic pale fibers, arrow), phagocytosis (arrow head), and endomysial fibrosis in a patient with dystrophinopathy type Duchenne muscular dystrophy. e Ragged red fiber (arrow) in patient with mitochondriopathy type progressive external ophthalmoplegia. $\mathbf{f}$ Glycogen subsarcolemal accumulation in patient with type $\mathbf{V}$ glycogenosis (McArdle disease). $\mathbf{g}$ Negative myophosphorylase reaction in McArdle disease (inset is normal control). $\mathbf{h}$ Lipid accumulation in patient with mitochondriopathy. $\mathbf{i}$ nemaline rods (arrow) in patient with congenital nemaline myopathy, $\mathbf{j}$ COX negative fibers (SDH reactive in blue, arrow) in patient with mitochondriopathy subtype progressive external ophthalmoplegia. $\mathbf{k}$ Clear central areas devoid of oxidative reaction (core, arrow) in central core congenital myopathy. I Large groups of type 2 atrophic (arrow) and large groups of type 1 hypertrophic fibers in patient with neurogenic abnormality. (a. HE 100x, b. Gomori modified trichrome 400x, c. HE 400x, d. HE 200x, e. Gomori modified trichrome 400x, f. PAS 400x, g. myophosphorylase 100x, h. Oil-red-O 400x, i. Gomori modified trichrome 200x, j. COX-SDH double reaction 100x, k. SDH 400x, I. ATPase 9.4200x) 

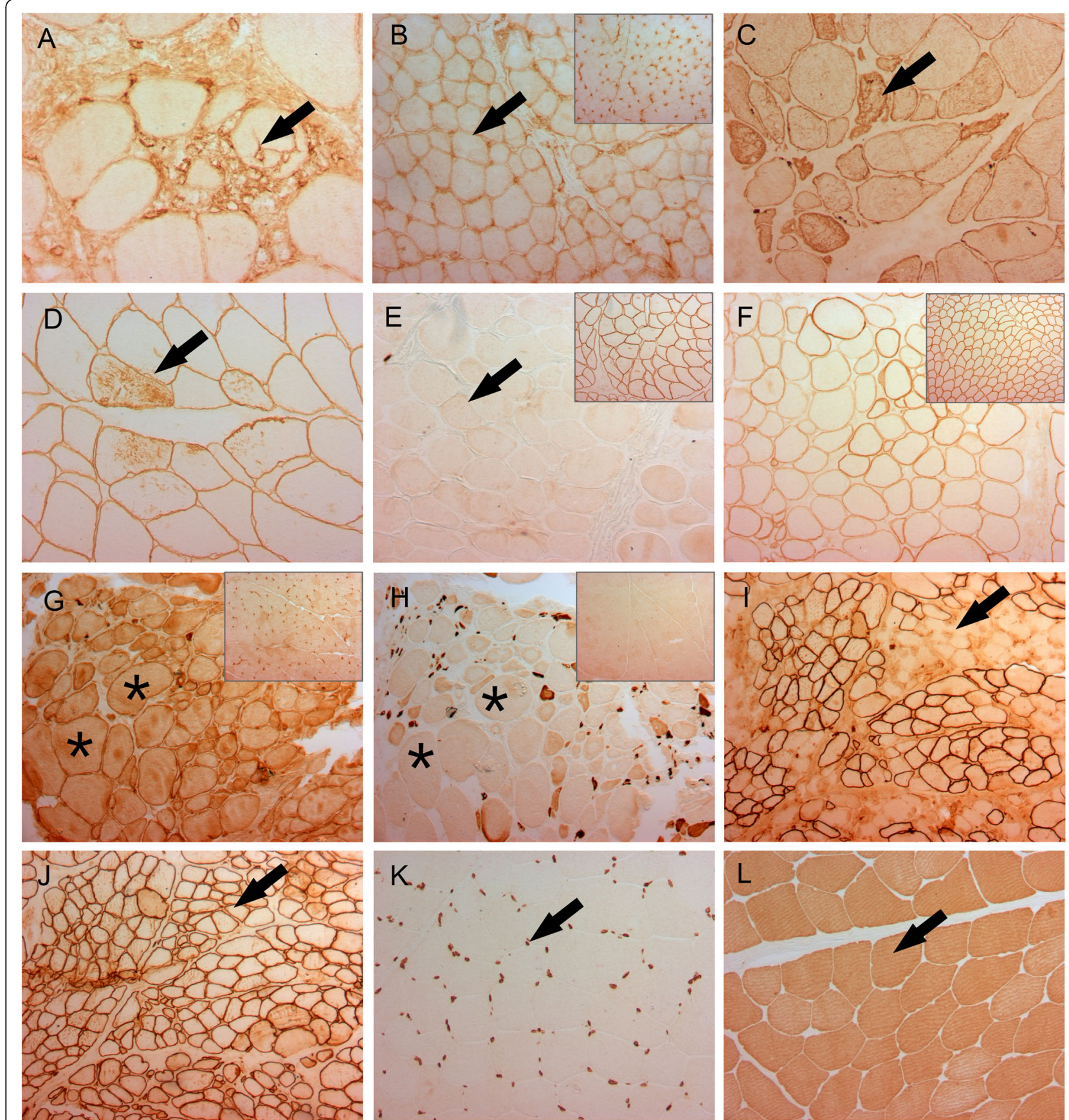

Fig. 5 Immunohistochemical evaluation. a Invasion (arrow) of non-necrotic muscle fiber by cytotoxic/ supressor CD8 positive T lymphocytes in a patient with sporadic inclusion body myositis. b Abnormal sarcolemmal positivity for major histocompatibility complex class I (MHC-I) in patient with dermatomyositis (inset shows normal control with blood vessel wall reaction). c Intrasarcoplasmic desmin reactive (arrow) material in patient with myofibrillar myopathy. $\mathbf{d}$ Ectopic intrasarcoplasmic dystrophin expression in patient with myofibrillar myopathy. e Complete immunohistochemical dystrophin deficiency in patient with dystrophinopathy type Duchenne muscular dystrophy (inset shows normal control). f Decreased dystrophin reaction in patient with dystrophinopathy type Becker muscular dystrophy. $\mathbf{g}$. and $\mathbf{h}$ Serial sections showing abnormal utrophin reaction (g) in sarcoplasmic membranes of some fibers (asterisks) without signs of regeneration, negative for neonatal myosin (h) in patient with dystrophinopathy type Becker (insets are normal controls). $\mathbf{i}$ and $\mathbf{j}$. serial sections of negative fibers in mosaic pattern in fibers without necrosis (with sarcolemma positive for spectrin in $\mathbf{j}$ ) in a female symptomatic carrier of dystrophinopathy. $\mathbf{k}$ normal emerin immunophenotypic expression in nuclear membrane (arrow). I. normal sarcomeric (intrasarcoplasmic) telethonin expression (arrow). a. CD8 400x, b. MHC-1 200x (inset normal control original magnification MHC-1 200x), c. desmin 200x, d. dystrophin carboxy-terminal DYS2 200x, e. dystrophin carboxy-terminal DYS2 200x, f. dystrophin amino-terminal DYS3 200x, g. utrophin 100x, h. neonatal myosin 100x, i. dystrophin amino-terminal DYS3 100x, j. spectrin 100x, k. emerin 200x, I. telethonin 200x 

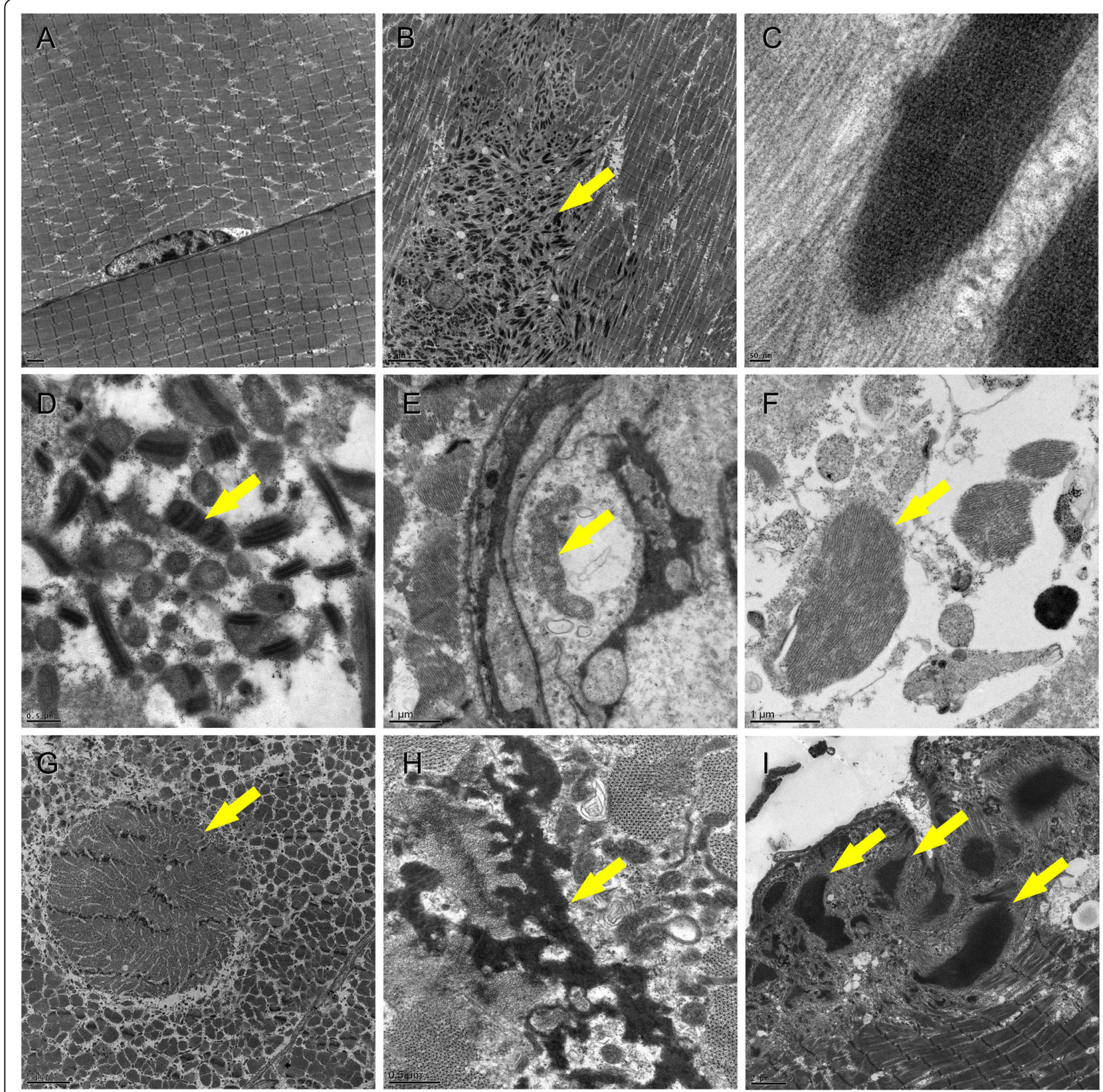

Fig. 6 Ultrastructural evaluation. a. almost normal ultrastructural morphologic pattern. b. nemaline rods are rod shaped structures (arrows), c. lattice structure similar to $\mathbf{Z}$ disks in nemaline bodies in a patient with nemaline congenital myopathy. $\mathbf{d}$. abnormal mitochondrial accumulation with paracrystalline inclusions (arrow) in patient with mitochondriopathy subtype progressive external ophthalmoplegia. e. tubulorreticular inclusions (arrow) inside vessel wall endothelial cell cytoplasm in patient with dermatomyositis. f. 15 to $18 \mathrm{~nm}$ filamentous inclusion (arrow) in patient with sporadic inclusion body myositis. $\mathbf{g}$. area of myofibrillar disorganization (arrow) with few mitochondria (core) in central core congenital myopathy. $\mathbf{h}$. electrondense amorphous deposit (arrow) in patient with myofibrillar myopathy. i. elongated electrondense masses (arrows) in patient with myofibrillar myopathy. (Transmission electron microscopy a. 2500x, b. 2500x, c. 150,000x, d. 25,000x, e. 15,000x, f. 20,000x, g. $2500 x$, h. 30,000x, i. 5000x)

In our service, after the implementation of routine muscle imaging studies prior to muscle biopsy, the number of inadequate or end-stage biopsy specimens dropped to less than $0.4 \%$ during the last 10 years $(n=$ 804). All muscle imaging exams have been revised by both radiologists and pathologists in advance in order to determine the most suitable muscle biopsy site. For patients with advanced muscle fat replacement, an ultrasound guided muscle biopsy has been performed (Cotta et al. 2014a, 2014b).

There is consensus in the literature, that the muscle submitted to biopsy may present intermediate force. The 
Table 1 Useful free myology websites and information sources

http://anatpat.unicamp.br/eneuromusc.html

http://neuromuscular.wustl.edu/lab/mbiopsy.htm

https://www.jove.com/video/51586/

https://www.ncnp.go.jp/nin/guide/r1/video_e.html

http://www.scielo.br/pdf/rba/v63n1/en_v63n1a02.pdf

Malignant hyperthermia Hotline phone +55-11-55759873

http://www.musclegenetable.fr.

muscle submitted to biopsy may not be too weak or too strong. Some authors recommend grade 3 or 4 muscle strength as determined on neurological examination using the MRC (Medical Research Council) scale (Pasnoor and Dimachkie 2019) (Table 2) (Engel and Franzini-Armstrong 2004), whereas others recommend grade 4 or 5 (Amato and Russell 2008).

Whenever available, muscle imaging exams may direct the investigation to muscles with intermediate muscle fat replacement. The muscle chosen for muscle biopsy may be superficial and easily accessible to the surgeon, and the most commonly biopsied are vastus lateralis and biceps brachialis. In special situations, deltoid, triceps brachialis, rectus femoris, soleus, tibialis anterior, gastrocnemius (Loughlin 1993) and short peroneus (Amato and Russell 2008) may be chosen. In patients with suspicion of distal myopathy, soleus, tibialis anterior, gastrocnemius, carpal radial extensor, and extensor digitorum longus may be biopsied (Engel and Franzini-Armstrong 2004; Amato and Russell 2008).

Muscle fibers are classified in two great groups as type 1 or type 2 . Type 1 fibers are predominantly aerobic whereas type 2 are predominantly glycolytic. The percentage of each muscle type may vary for each specific muscle (Table 3).

The distinction between fiber types is very useful for the detection of: a) fiber type predominance, b) fiber type disproportion, c) selective fiber type atrophy, and d) fiber type grouping (Figs. 3 and 4).

Fiber type predominance is detected when the mean number of type 1 or type 2 fibers is $20 \%$ higher than the expected mean for a given muscle (Table 3) (Loughlin

Table 2 Muscle strength grading according to MRC (Muscle Research Council) (Pasnoor and Dimachkie 2019)

\begin{tabular}{ll}
\hline Grade & Muscle movement on neurologic examination \\
\hline 1 & Trace contraction of the muscle \\
2 & Ability to move with gravity eliminated \\
3 & Active movement against gravity \\
4 & $\begin{array}{l}\text { Ability to move the joint against combination of gravity and } \\
\text { some resistance }\end{array}$ \\
\hline
\end{tabular}

1993; Dastgir et al. 2016; Cotta and Paim 2016). For vastus lateralis and biceps brachialis, the percentage of muscle fiber types is usually of: one type 1 fiber for two type 2 fibers. Type 1 fiber predominance is very common in congenital myopathies, but it also reflects long standing myopathic processes, as in some types of muscular dystrophies (Paim et al. 2013).

Fiber type disproportion reflects a morphometric measure that quantifies how much type 1 fibers are smaller than type 2 fibers (see section Morphometry below). Congenital fiber type disproportion presents type 1 fiber predominance and almost all type 1 fibers are smaller than type 2 fibers (Clarke 2011; Dubowitz et al. 2020).

Selective fiber type atrophy is usually considered when isolated fibers of one type are smaller than the other fiber type. Selective type 2 fiber atrophy although unspecific, is very common in corticosteroid induced toxic myopathy, and congenital myasthenic syndromes (Engel and Franzini-Armstrong 2004; Scola et al. 2007; Dubowitz et al. 2013; Dubowitz et al. 2020).

Fiber type grouping is the morphological hallmark or neurogenic disorders (Engel and Franzini-Armstrong 2004; Karpati et al. 2010; Dubowitz et al. 2020; Dubowitz et al. 2013; Dubowitz and Sewry 2007; Dubowiz 1995; Dubowitz and Brooke 1973; Loughlin 1993; Anderson 1985; Amato and Russell 2008). It is characterized by large groups of each fiber type, that are formed during the process of reinnervation (Fig. 4).

In special situations, it may be difficult to differentiate which is the weaker muscle within a muscle group. Detailed clinical exam with inspection and palpation may provide useful data on muscle trophism. Sometimes imaging studies may be very useful for this evaluation, as observed in the example depicted in Fig. 1. Physical examination disclosed a quadriceps muscle with grade 4 strength (Table 2). A vastus lateralis muscle biopsy could have provided an inadequate sample or end-stage muscle sample with extensive fibrous-fat replacement simulating a muscular dystrophy. On the contrary, a rectus femoris muscle biopsy provided an excellent sample that disclosed type 1 fiber predominance and almost all fibers with "central cores", confirming the diagnosis of central core congenital myopathy (Fig. 1).

Facial, cervical and hand intrinsic muscles are not usually biopsied due to functional and aesthetic reasons (Engel and Franzini-Armstrong 2004). It is important to perform the muscle biopsy on a contralateral muscle to the side submitted to injections on neurophysiological studies, in order to avoid needle artifacts such as inflammatory infiltrate (Engel and Franzini-Armstrong 2004; Amato and Russell 2008). It is believed that the 
Table 3 Muscle fiber type percentage by muscle site (Loughlin 1993; Dastgir et al. 2016; Cotta and Paim 2016)

\begin{tabular}{|c|c|c|c|c|}
\hline \multirow[t]{2}{*}{ Muscle group } & \multicolumn{2}{|c|}{ Mean (\%) } & \multicolumn{2}{|c|}{ Predominance (\%) } \\
\hline & Type 1 & Type 2 & Type 1 & Type 2 \\
\hline Biceps brachii (surface) & 42.3 & 57.7 & $>62.3$ & $>77.7$ \\
\hline Biceps brachii (deep) & 50.5 & 49.5 & $>70.5$ & $>69.5$ \\
\hline Brachioradialis & 39.8 & 60.2 & $>59.8$ & $>80.2$ \\
\hline Deltoid (superficial) & 53.3 & 46.7 & $>73.3$ & $>66.7$ \\
\hline Deltoid (deep) & 61.0 & 39.0 & $>81.0$ & $>59.0$ \\
\hline Extensor digitorum & 47.3 & 52.7 & $>67.3$ & $>72.7$ \\
\hline Extensor digitorum brevis & 45.3 & 54.7 & $>65.3$ & $>74.7$ \\
\hline Gastrocnemius (lateral head surface) & 43.5 & 56.5 & $>63.5$ & $>76.5$ \\
\hline Gastrocnemius (lateral head deep) & 50.3 & 49.7 & $>70.3$ & $>69.7$ \\
\hline Gastrocnemius (medial head) & 50.8 & 49.2 & $>70.8$ & $>69.2$ \\
\hline Peroneus longus & 62.5 & 37.5 & $>82.5$ & $>57.5$ \\
\hline Rectus femoris (lateral head surface) & 29.5 & 70.5 & $>49.5$ & $>90.5$ \\
\hline Rectus femoris (lateral head deep) & 42.0 & 58.0 & $>62.0$ & $>78.0$ \\
\hline Rectus femoris (medial head) & 42.8 & 57.2 & $>62.8$ & $>77.2$ \\
\hline Tibialis anterior (surface) & 73.4 & 26.6 & $>93.4$ & $>46.6$ \\
\hline Tibialis anterior (deep) & 72.7 & 27.3 & $>92.7$ & $>47.3$ \\
\hline Triceps brachii (surface) & 32.5 & 67.5 & $>52.5$ & $>87.5$ \\
\hline Triceps brachii (deep) & 32.7 & 19.6 & $>52.7$ & $>39.6$ \\
\hline Vastus lateralis (surface) & 37.8 & 67.3 & $>57.8$ & $>87.3$ \\
\hline Vastus lateralis (deep) & 46.9 & 53.1 & $>66.9$ & $>73.1$ \\
\hline
\end{tabular}

inflammatory infiltrate may last for at least 4 or 6 weeks after electromyogram (Engel and Franzini-Armstrong 2004).

In cases suspicious of congenital myasthenic syndromes, ultrastructural evaluation of neuromuscular junctions should be performed in part of the sample immediately fixed in glutaraldehyde for electron microscopy studies. Exceptionally, a small formalin fixed sample should be submitted to ultrastructural studies in search of neuromuscular junctions.

For patients under investigation of malignant hyperthermia, it is recommended to search for a specialized center equipped to perform the test (da Silva et al. 2013) (Table 1).

\section{What is necessary to do in advance to the muscle biopsy procedure?}

Before the performance of the muscle biopsy, it is advisable to get in touch with the laboratory that will receive the patient or the muscle biopsy. It is mandatory to ask if the laboratory is equipped to perform histochemical and immunohistochemial studies in liquid nitrogen frozen muscle. As fixation in formalin precludes the performance of histochemical and various immunohistochemical techniques, muscle biopsies should not be entirely formalin fixed and paraffin embedded. In an ideal situation a small sample is fixed in glutaraldehyde for eventual EM (electron microscopy) studies and the most substantial portion is frozen in liquid nitrogen (Fig. 1). Nowadays, liquid nitrogen frozen specimens are the only way to preserve histochemical and immunohistochemical muscle biopsy properties for neuromuscular investigation (Engel and Franzini-Armstrong 2004; Karpati et al. 2010; Dubowitz et al. 2013; Dubowitz and Sewry 2007; Dubowiz 1995; Dubowitz and Brooke 1973; Loughlin 1993; Anderson 1985; Amato and Russell 2008; Levy 1978; Dastgir et al. 2016; Fardeau 2017; Malfatti and Romero 2017).

\section{How to perform the muscle biopsy surgical procedure and specimen handling?}

The surgeon prepares the procedure without cauterization of the muscle tissue, only the blood vessels of the subcutaneous tissue should be cauterized. The anesthetic should not be infiltrated inside the muscle sample, in order to avoid artifacts that should preclude adequate analysis. The skin is cleaned with antiseptic solution. The skin and muscle fascia are infiltrated with anesthetic, and the muscle is sectioned in the same direction of the fascicles of the muscle fibers in order to perform transverse and longitudinal sections. After excision, the muscle is gently accommodated on a slightly moist gauze. Immediately, one to four $0.1 \times 0.1 \mathrm{~cm}$ 
Table 4 Selected routine muscle stains and histochemical reactions (Dubowitz et al., 2020; Loughlin 1993; Udd et al. 2019)

\section{1) Hematoxylin and eosin (HE)}

General architecture, regeneration, necrosis, phagocytosis, perifascicular atrophy, nuclear internalization, rimmed vacuoles, and inflammation (Figs. 3 and 4).

\section{2) Gomori modified trichrome:}

Muscle fibers sarcoplasm is blue-green, nuclei are red, and collagen is light green (Figs. 3 and 4). Sarcoplasmic reticulum, mitochondria, tubular aggregates, cytoplasmic bodies and reducing bodies are dark red (Dubowitz et al., 2020; Loughlin 1993).

Congenital nemaline myopathy derives from the greek word "nema" that means "thread" (Dubowitz et al., 2020), that presents rod structures that may be observed in red on the Gomori modified trichrome stain (Fig. 4). On electron microscopy, these structure are electrondense rods with a lattice structure similar to the Z disks of the sarcomere (Fig. 6).

In mitochondrial myopathies, ragged red fibers, correspond to mitochondrial proliferation (Fig. 4).

\section{3) Periodic acid Schiff (PAS) without and with diastase:}

Glycogen, neutral mucopolysacarides, glycoproteins, mucoproteins, glycoproteins, glycolipids, some insaturated lipids and phopholipids (Figs. 3 and 4) (Dubowitz et al., 2020; Loughlin 1993). The evaluation of PAS and PAS with diastase (glycogen is diastase labile) stains is useful to the diagnosis of glycogenoses with intrasarcoplasmic glycogen accumulation (Fig. 4).

\section{4) Oil-red-O or Sudan-black:}

Neutral lipids stain red (Oil-red-O) (Figs. 3 and 4) or black (Sudan black).

\section{5) Succinate dehydrogenase (SDH)}

Enzymatic activity of the nuclear encoded mitochondrial respiratory chain complex II that reacts selectively with mitochondria (Figs. 3 and 4) (Dubowitz et al., 2020; Loughlin 1993). It is very useful for the diagnosis of mitochondrial myopathies.

\section{6) Cytochrome-c-oxidase (COX):}

Enzymatic activity of the mitochondrial encoded respiratory chain complex IV that reacts selectively with mitochondria (Figs. 3 and 4) (Dubowitz et al., 2020; Loughlin 1993).

\section{7) Combined Cytochrome-c-oxidase/ succinate dehydrogenase (double COX-SDH)}

Histochemical reactions performed in sequence on the same frozen section that permits the visualization of COX negative fibers with retention of SDH activity, useful for the diagnosis of mitochondrial myopathies (Fig. 4).

\section{8) Nicotinamide adenine dinucleotide (NADH)}

Oxidative enzyme on mitochondrial and endoplasmic reticulum, that is located in the sarcoplasm. It is very useful to demonstrate the muscle fiber intermyofibrillar network (Figs. 3 and 4) (Dubowitz et al., 2020; Loughlin 1993).

Congenital central core myopathy presents clear or empty areas on oxidative reactions COX, SDH, and NADH (Figs. 1 and 4). The name central core was given to this round structure that may sometimes occupy the central part of the muscle fibers and they may be visualized on transversal a longitudinal section (Figs. 3 and 4) (Dubowitz et al., 2020). However, these structure may present either central or peripheral disposition. On electron microscopy, these structures correspond to areas of myofibrillar disorganization with absence of scarcity of mitochondria and sarcoplasmic reticulum, that are responsible for the oxidative reactions (Figs. 1 and 6) (Dubowitz et al., 2020).

\section{9) Myosinic ATPase}

Differentiation of muscle fiber types. In normal muscle, muscle fibers types are alternately organized in a checkerboard pattern (Figs. 3 and 4) (Dubowitz et al., 2020; Loughlin 1993). The type of the fiber is determined by the motor neuron that innervates each fiber and varies in each muscle (Table 3). This reaction if useful to demonstrate type grouping in neurogenic muscle abnormalities (Fig. 4). Type 1 fiber predominance is common in congenital myopathies. In congenital fiber type disproportion, there is type 1 fiber predominance and atrophy.

\section{0) Acid phosphatase:}

Areas of increased lysosomal activity, necrotic fibers, and lipofuscin. It is very useful for the diagnosis of glycogenosis type II (Pompe disease) and some vacuolar myopathies (Dubowitz et al., 2020; Loughlin 1993).

\section{1) Myophosphorylase}

Enzyme present in the intermyofibrillar space aqueous sarcoplasm (Loughlin 1993). Its deficiency is useful for the diagnosis of glycogenosis type $\mathrm{V}$ (McArdle disease) (Fig. 4) (Dubowitz et al., 2020).

\section{2) Phosphofructokinase:}

The reaction may be absent in patients with glycogenosis type VII (Tarui disease) (Dubowitz et al., 2020).

\section{3) Myoadenylate deaminase}

The histochemical reaction that may be absent in some patients with exertional myalgia (Dubowitz et al., 2020).

\section{4) Nonspecific esterase:}

This stain highlights neuromuscular junctions, myotendinous junctions, phagocytosis, and small angulated denervated fibers (Dubowitz et al., 2020).

\section{5) Alkaline phosphatase:}

It highlights the normal blood vessels and it is increased in the perimysium in some inflammatory myopathies (Dubowitz et al., 2020).

\section{6) Menadione-linked alpha-glycerophosphate:}

This stain is very useful for the diagnosis of reducing body myopathy (Dubowitz et al., 2020).

\section{7) Congo red:}

This stain that permits the visualization of amyloid deposits (Dubowitz et al., 2020). 
Table 5 Rimmed vacuoles in muscle biopsies: selected differential diagnosis

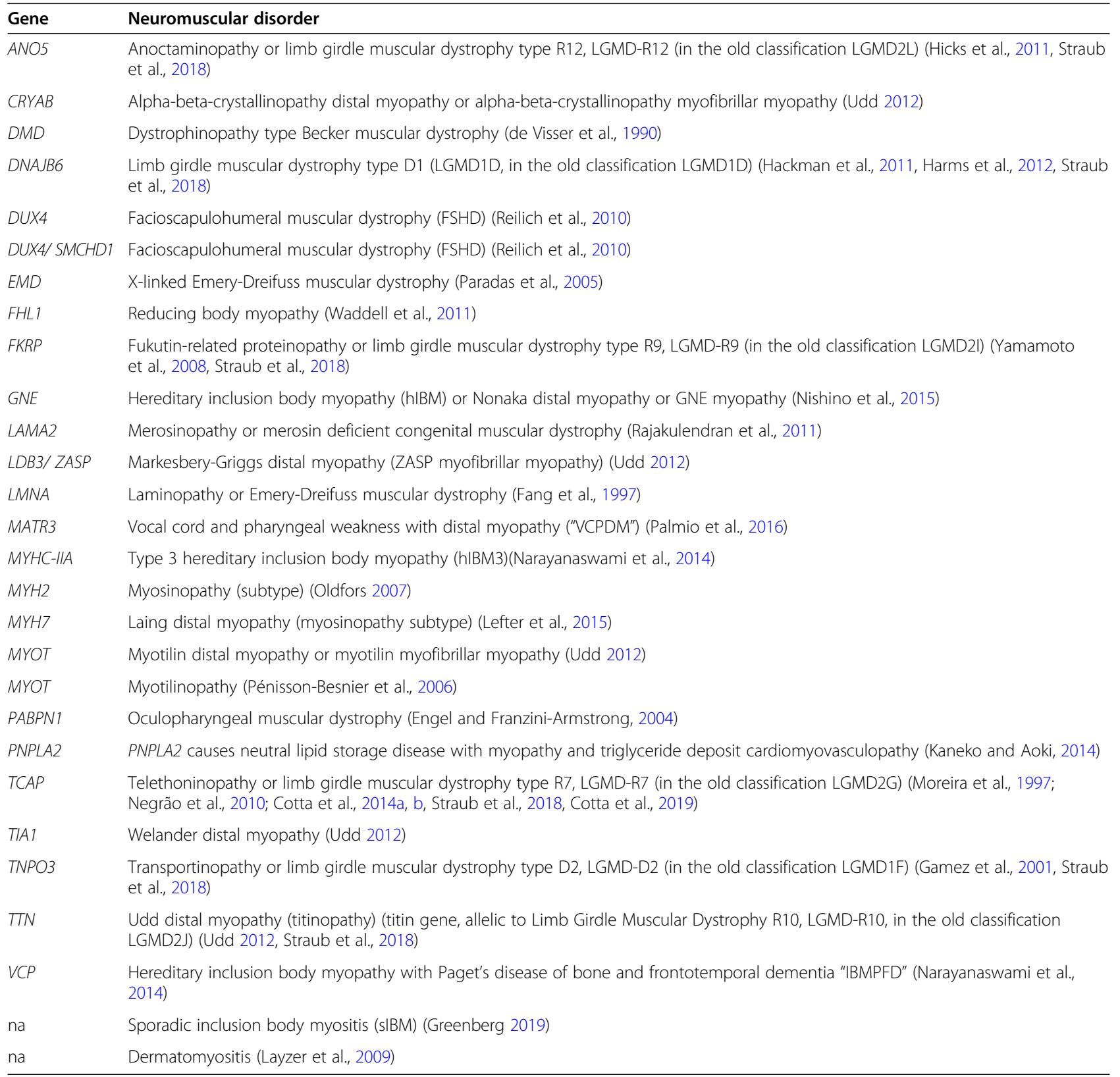

fragments are fixed in glutaraldehyde for electron microscopy, whenever possible. A muscle fragment is formalin fixed for transverse and longitudinal sections. About 80 to $90 \%$ of the muscle sample is liquid nitrogen frozen. Special recommendations for this procedure may be found in the didactic videos following the World Muscle Society instructions (Table 1) (Engel and Franzini-Armstrong 2004; Karpati et al. 2010; Dubowitz et al. 2013; Dubowitz and Sewry 2007; Dubowiz 1995; Dubowitz and Brooke 1973; Loughlin 1993; Anderson 1985; Amato and Russell 2008; Levy 1978; Dastgir et al. 2016; Fardeau 2017; Malfatti and Romero 2017). It is important to avoid freezing artifacts and most reference laboratories use isopentane precooling for this purpose (Table 1). An adaptation of these procedures using talcum powder has been used with success in a reference center for more than three decades (Fig. 2) with satisfactory morphological (Figs. 3, 4, and 5) results (Werneck and Silvado 1981; So 1985). This procedure has also been useful for complementary mitochondrial respiratory chain, Western blot, and Southern blot studies, performed on archived remaining muscle tissue stored either in liquid nitrogen containers or in $-80{ }^{\circ} \mathrm{C}$ freezer (Figs. 1 and 2). 
Table 6 Neuromuscular immunohistochemistry: selected antibodies (Dubowitz et al., 2020; Dubowitz et al., 2013; Paradas et al., 2005; Dastgir et al. 2016; Udd et al. 2019)

\begin{tabular}{|c|c|}
\hline & Reactic \\
\hline \multicolumn{2}{|l|}{ Dystrophinopathies } \\
\hline Spectrin (sarcoplasmic membrane integrity marker) & SM \\
\hline Dystrophin Rod domain (DYS1) & SM \\
\hline Dystrophin carboxy-terminal (DYS2) & SM \\
\hline Dystrophin amino-terminal (DYS3) & SM \\
\hline Utrophin & SM \\
\hline Neonatal myosin & S/ RF \\
\hline \multicolumn{2}{|l|}{ Other muscular dystrophies } \\
\hline Spectrin (sarcoplasmic membrane integrity marker) & SM \\
\hline Alpha-sarcoglycan & SM \\
\hline Beta-sarcoglycan & SM \\
\hline Gamma-sarcoglycan & SM \\
\hline Delta-sarcoglycan & SM \\
\hline Dysferlin & SM \\
\hline Caveolin & SM \\
\hline Telethonin & S \\
\hline Emerin & NM \\
\hline Collagen VI & EM \\
\hline Laminin alpha 5 & EM \\
\hline Laminin beta 1 & EM \\
\hline Laminin gamma 1 (extracellular matrix integrity marker) & EM \\
\hline Merosin (alpha-2 laminin) (80 kDa, 300 kDa) & EM \\
\hline Integrin alpha-7 & SM \\
\hline Alpha-dystroglycan (VIA4, IIH6C4) & EM \\
\hline Beta-dystroglycan & SM \\
\hline nNOS (neuronal nitric oxide synthase) & SM \\
\hline \multicolumn{2}{|l|}{ Inflammatory myopathies } \\
\hline CD3 & TL \\
\hline CD4 & $\mathrm{TL}$ \\
\hline CD8 & TL \\
\hline CD20 & $B L$ \\
\hline CD138 & $P$ \\
\hline CD45 & $\mathrm{TL} / \mathrm{BL}$ \\
\hline CD68 & Mac \\
\hline CD31 & C \\
\hline MHC-I & C \\
\hline p62 & A \\
\hline C5b-9 & C \\
\hline \multicolumn{2}{|l|}{ Myofibrillar myopathies } \\
\hline Desmin & $\mathrm{S}$ \\
\hline Myotilin & $S$ \\
\hline Beta-crystallin & $\mathrm{S}$ \\
\hline
\end{tabular}

Table 6 Neuromuscular immunohistochemistry: selected antibodies (Dubowitz et al., 2020; Dubowitz et al., 2013; Paradas et al., 2005; Dastgir et al. 2016; Udd et al. 2019) (Continued)

\begin{tabular}{|c|c|}
\hline & Reaction \\
\hline \multicolumn{2}{|c|}{ Sporadic inclusion body myositis } \\
\hline Ubiquitin & S \\
\hline \multicolumn{2}{|l|}{ Myosins } \\
\hline Rapid myosin & S \\
\hline Slow myosin & S \\
\hline Embryonic myosin & S \\
\hline Fetal myosin & S \\
\hline
\end{tabular}

Reaction = immunohistochemistry reaction pattern. $S M$ sarcoplasmic membrane, $S$ sarcoplasm, $E M$ extracellular matrix, NM nuclear membrane, $L$ lymphocyte, $T L T$ lymphocyte, $B L$ B lymphocyte, $T L / B L T$ and B lymphocytes, $C$ capillary vessel wall, $P$ plasma cell (Dastgir et al., 2016), $R F$ regeneration fiber, Mac macrophage, $A$ aggregates

The talcum powder technique is based on the principle of "powder coat ultrarapid freezing", that prevents the appearance of artifacts caused by ice crystals (Moline and Glenner 1964; Werneck and Silvado 1981; So 1985). In brief (Fig. 2): (1) prepare the intraoperative laboratory room where the cryostat is located with: Petri dish; tweezers; sharp blades; cryotubes; a glutaraldehyde tube (Eppendorf size type); cork disks identified with the number of the muscle biopsy and the initials of the patients written in a white adhesive surgical tape wrapped around the cork disk; unscented dry talcum powder (Hydrous Magnesium Silicate); OCT (optimal cutting temperature) mounting medium; glass slides; coverslips; and HE (hematoxylin and eosin) staining kit; (2) after the extraction of the muscle in the operating room, the fragment is involved in a gauze slightly moisted in saline for transport to the intraoperative laboratory room, located inside the surgical center; (3) the muscle inside the gauze is placed over a Petri dish; (4) the muscle is separated from the gauze; (5) one to four $0.1 \times 0.1 \mathrm{~cm}$ muscle fragments are cut from the muscle sample and immediately immersed in $2 \%$ glutaraldehyde; (6) the fresh muscle tissue is oriented according to the muscle fiber direction, if necessary, to make a transverse frozen muscle block; (7) one extremity of the fragment is chosen to serve as the base of the frozen block; (8) the fresh muscle sample is covered in all sides, except the base, by a generous amount of dry talcum powder; (9) optimal cutting temperature (OCT) mounting medium is applied on the surface of the previously identified cork; (10) the mounting medium is used to connect the base of the block to the previously identified cork disk; (11) the cork disk with the muscle is immersed in liquid nitrogen for 10 to $15 \mathrm{~s}$; (12) all excess of talcum powder should be mechanically removed with a precooled blade before performing the cryostat sections; (13) the remaining fresh muscle tissue without talcum is frozen 
Table 7 Immunohistochemistry and Western blot secondary antibody deficiency

\begin{tabular}{ll}
\hline Antibody & Primary myopathy \\
\hline Calpain & Dysferlinopathy or LGMD-R2 dysferlin-related (Anderson et al., 2000) \\
& Fukutin-related proteinopathy or LGMD-R9 FKRP-related (Yamamoto et al., 2008) \\
& Titinopathy or LGMD-R10 titin-related (Pénisson-Besnier et al., 2010; Udd et al., 2005) \\
& Anoctaminopathy or LGMD-R12 anoctamin-related (Penttilä et al., 2012) \\
& Calpainopathy or LGMD-R1 calpain-related (Anderson et al., 2000, Groen et al., 2007) \\
Dysferlin & Caveolinopathy (Müller et al., 2006, Matsuda et al., 2001) \\
& Dystrophinopathy or Duchenne/ Becker muscular dystrophy (Izumi et al., 2015) \\
& Sarcoglycanopathy or LGMD-R3-R4-R5-R6 or alpha, beta, gamma, delta sarcoglycan-related (Izumi et al., 2015) \\
& Anoctaminopathy or LGMD-R12 anoctamin-related (Izumi et al., 2015) \\
GNE myopathy or Nonaka distal myopathy (Izumi et al., 2015) \\
Myotilinopathy (Izumi et al., 2015) \\
Dysferlinopathy or LGMD-R2 dysferlin-related (Barresi 2011)
\end{tabular}

Calpain deficiency detectable by Western blot

in cryotubes for molecular or respiratory chain enzymatic studies whenever appropriate; (14) if there is remaining fresh muscle, procedures " 6 " to " 11 " should be performed for additional transverse or longitudinal muscle blocks; (15) the transverse muscle block is cut at - $24{ }^{\circ} \mathrm{C}$ inside the cryostat with 8 to $10 \mu \mathrm{m}$ thickness; (16) a slide with a section correspondent to the first transverse muscle block should be prepared and HE stained, in order to give information about sample adequacy to the surgeon, and to elaborate the intraoperative report; (17) one section of each muscle block should be cut and stained with HE; (18) a muscle sample is fixed in buffered formaline; (19) all numbers and letters written to identify the patient sample should be checked again on the tubes and cork disks, carefully, before storage either in liquid nitrogen containers or in $-80{ }^{\circ} \mathrm{C}$ freezer.
The talcum powder technique was chosen in our laboratory based on three negative characteristics from isopentane. Isopenate is more expensive, it presents potential explosion hazard, and it presents slower ultrarapid freezing properties. According to Moline and Glenner (1964), powder coated liquid nitrogen achieved - $50{ }^{\circ} \mathrm{C}$ between 17 and $26 \mathrm{~s}$, while isopentane cooled liquid nitrogen achieved the same temperature only after 34 to $74 \mathrm{~s}$. The option to choose between the talcum powder technique over the well known isopentane precooled technique should be careful. The talcum powder technique should be used only if the technician is instructed to mechanically remove all excess of talcum powder using a precooled blade. Slide artifacts may be created due to the abrasion of talcum against the cutting blade if it is not appropriately removed.

Table 8 Morphometric muscle biopsy values (Bernier et al., 2002; Clarke 2011; Dubowitz et al., 2020)

\begin{tabular}{|c|c|c|}
\hline \multicolumn{3}{|c|}{ Fiber size disproportion quotient } \\
\hline$\frac{(\text { Type 2D - Type 1D) }}{\text { Type 2D }}$ & & $\begin{array}{l}\text { Dubowitz cri } \\
\text { Clarke criteri }\end{array}$ \\
\hline \multicolumn{3}{|c|}{ Mean type 2 fiber diameter $=$ Type $2 \mathrm{D}$} \\
\hline \multicolumn{3}{|c|}{ Mean type 1 fiber diameter $=$ Type 1D } \\
\hline \multicolumn{3}{|c|}{ Mitochondrial disorder diagnostic criteria } \\
\hline Below 16 yo & More than $2 \%$ subsarcolemmal accumulation & minor criteria \\
\hline Below 30 yo & Any ragged red fiber & minor criteria \\
\hline Between 30 and 50 yo & $1-2 \%$ ragged red fibers & minor criteria \\
\hline Any age & More than $2 \%$ ragged red fibers & major criteria \\
\hline Below 50 yo & More than $2 \%$ COX negative fibers & major criteria \\
\hline Above 50 yo & More than $5 \%$ COX negative fibers & major criteria \\
\hline
\end{tabular}

Fiber size disproportion quotient: Mean type 2 fiber (Type $2 \mathrm{D}$ ) diameter less mean type 1 fiber (Type 1 D) diameter; the difference is divided by the mean type 2 fiber diameter (Type 2 D). Fiber size disproportion is observed in all Congenital Fiber Type Disproportion patients, but many other conditions may present fiber size disproportion (nemaline myopathy, Steinert myotonic dystrophy, Spinal Muscular Atrophy) (Clarke 2011); yo: years old; subsarcolemal accumulations: mitochondrial subsarcolemal accumulations on SDH reaction. Ragged-red fibers are usually quantified as ragged-red equivalent or ragged-blue fibers on SDH reaction characterized by marked subsarcolemal and intrasarcoplasmic mitochondrial proliferation 
Table 9 Rationale for myopathy investigation

1. Complete anamnesis and neurological physical examination;
2. Family history with pedigree;
3. Exclude four common neuromuscular diagnosis that may be
diagnosed clinically and confirmed by molecular studies:
- Spinal muscular atrophy (SMA)
- Myotonic dystrophy type 1 (DM1, Steinert's myotonic dystrophy)
- Facioscapulohumeral muscular dystrophy (FSHD)
- Dystrophinopathy type Duchenne muscular dystrophy
4. Electromyogram;
5. Muscle serum enzymes: creatine kinase, aldolase;
6. Muscle imaging: magnetic resonance imaging (MRI), ultrasound,
ocasionally computed tomography for patients that cannot be
submitted to MRI (e.g., pacemaker users, metal implants, etc.);
7. Brain imaging if suspected of encephalomyopathy.
8. According to the clinical suspicion: Muscle biopsy or Molecular
Studies such as Next Generation Sequencing (NGS) or targeted
molecular sequencing of the specific gene group related to muscle
biopsy findings.

\section{Intraoperative frozen section stained with hematoxylin and eosin (HE)}

Intraoperative frozen section is an excellent laboratorial practice for rapid laboratory and neurologic clinic staff communication. Immediately after the muscle biopsy procedure, liquid nitrogen frozen sections are $\mathrm{HE}$ stained. In few minutes, the valuable information about sample adequacy is provided for the surgeon while the patient is still inside the operative room. Therefore, the patient is given the possibility to have another adequate fragment extracted before the end of the surgery, if necessary.

Transverse HE stain permits the evaluation of the general architecture, muscle fibrous-fat replacement, fiber size and shape, number and position of the nucleus, sarcoplasmic basophilia (bluish stain) indicative of regeneration, necrosis, and phagocytosis, perifascicular atrophy, nuclear internalization, and rimmed vacuoles (Fig. 4) (Dubowitz et al. 2020; Loughlin 1993). Longitudinal HE sections provide means to evaluate larger muscle segments in order to identify focal inflammation and nuclear internalization such as nuclear chains (e.g., congenital myotubular myopathy).

\section{Which exams should be performed on the muscle biopsy specimen?}

Hematoxylin and eosin, histochemical stains and reactions, morphometry, immunohistochemistry, immunofluorescence, electron microscopy, mitochondrial respiratory chain enzymatic studies, muscle tissue molecular studies (Western blot, Southern blot), and histopathological study of paraffin embedded material (Tables 4, 5, 6, 7 and 8) (Figs. 3, 4, 5 and 6).
A fundamental part of morphologic muscle exam is the evaluation of muscle enzymes that are viable only in frozen unfixed sections as formalin fixation causes loss of reactivity.

The most common stains and reactions usually performed at a neuromuscular service are: hematoxylin and eosin (HE), Gomori modified trichrome, PAS (Periodic acid Schiff) with and without diastase, Oil-red-O or Sudan-black, SDH (succinate dehydrogenase), COX (cytochrome c oxidase), combined COX-SDH, NADH (nicotinamide adenine dinucleotide), myosinic ATPase, acid phosphatase, nonspecific esterase, myophosphorylase, phosphofructokinase, myoadenylate deaminase, alkaline phosphatase, menadione-linked alpha-glycerophosphate, and Congo red (Table 4) (Figs. 3 and 4).

\section{Special microscopic findings: rimmed vacuoles interpretation}

Rimmed vacuoles (Fig. 4) are abnormal empty spaces or cavities within the sarcoplasm, irregular or round, localized in any part of the fiber, in which the rim of the vacuole contains a basophilic granular material (HE) or red granular material (modified Gomori trichrome) (Engel and Franzini-Armstrong, 2004) (Fig. 4). They are not infrequent in myology practice but their identification should be a clue for the some specific diagnoses (Table 5).

Sporadic inclusion body myositis is one of the most common diagnoses in myopathology practice (Figs. 4, 5 and 6). A clinically defined diagnosis of sporadic inclusion body myositis is rendered when patients present, after the age of 45 years, for more than 1 year, muscle weakness that is worse on knee extension than hip flexion, and worse on finger flexion than on shoulder abduction, associated with serum creatine kinase increase of less than 15 times the reference value (Rose and ENMC IBM Working Group 2013). In this clinical setting, a muscle biopsy with endomysial lymphocytic inflammatory infiltrate invading nonnecrotic muscle fibers and rimmed vacuoles, that correspond to $15-18 \mathrm{~nm}$ filamentous inclusions on electron microscopy, allows to establish a definite diagnosis of sporadic inclusion body myositis (Figs. 4, 5 and 6) (Rose and ENMC IBM Working Group 2013; Van De Vlekkert et al. 2015).

Nevertheless, in other cases, when the clinical presentation is not characteristic of inclusion body myositis, it is important to be cautious. Rimmed vacuoles should not be considered sufficient for diagnosis of inclusion body myositis, as they have been reported in various muscle dystrophies, distal myopathies, and even in denervated muscles (Table 5, Hicks et al. 2011, Straub et al. 2018, Cotta et al. 2019, Udd 2012, de Visser et al. 1990, Hackman et al. 2011, Harms et al. 2012, Reilich et al. 2010, Paradas et al. 2005, Waddell et al. 2011, 
Yamamoto et al. 2008, Nishino et al. 2015, Rajakulendran et al. 2011, Fang et al. 1997, Palmio et al. 2016, Narayanaswami et al. 2014, Oldfors 2007, Lefter et al. 2015, Pénisson-Besnier et al. 2006, Engel and FranziniArmstrong 2004, Kaneko and Aoki 2014, Moreira et al. 1997; Negrão et al. 2010; Cotta et al. 2014a, 2014b, Gamez et al. 2001, Greenberg 2019, Layzer et al. 2009).

\section{Immunohistochemistry and immunofluorescence}

Either immunohistochemistry or immunofluorescence in frozen sections are diagnostic procedures that use antibodies directed to specific muscle tissue proteins, that may be absent, decreased or increased (Tables 6 and 7) (Fig. 5).

Immunohistochemistry is very useful for the diagnosis of dystrophinopathies (in cases where molecular exams are inconclusive), congenital muscular dystrophies, limb girdle muscular dystrophies, X-linked, and inflammatory myopathies (Table 5) (Dastgir et al. 2016; O'Connell et al. 2004).

Patients with sporadic inclusion body myositis may present invasion of nonnecrotic muscle fibers by $\mathrm{T}$ cell cytotoxic/ suppressor CD8 positive lymphocytes (Fig. 5) as well as abnormal expression of the major histocompatibility complex class I (MHC-I) on sarcoplasmic membranes (Fig. 5).

Myofibrillar myopathies may present abnormal intrasarcoplasmic deposits reactive for desmine as well as ectopic intrasarcoplasmic dystrophin reactivity, in contrast to normal sarcoplasmic membrane dystrophin expression (Fig. 5).

The different clinical presentations of dystrophinopathy may present different patterns of dystrophin expression. Patients with Duchenne muscular dystrophy usually present complete immunohistochemical dystrophin deficiency of three epitopes (Rod domain, carboxy-terminal and amino-terminal) (Fig. 5). Patients with less severe Becker muscular dystrophy clinical presentation may present partial or decreased immunohistochemical dystrophin expression (Fig. 5).

Some patients with Becker muscular dystrophinopathy present only slight dystrophin decrease, associated with abnormal sarcolemmal utrophin expression (Fig. 5). In normal conditions, utrophin is expressed only in neuromuscular junctions, blood vessel walls, and regenerating fibers (Karpati et al. 2010; Dubowitz et al. 2020). Therefore it is important to analyze both utrophin and neonatal myosin to identify regenerating fibers (Fig. 5). Patients with dystrophin deficiency present hyperexpression of utrophin, that is a dystrophin homologue codified on chromosome 6q24 (Karpati et al. 2010; Dubowitz et al. 2020).

Immunohistochemistry for nNOS (neuronal nitric oxide synthase) is also very useful for the diagnosis of patients with Becker muscular dystrophy (Table 6) (Dubowitz et al. 2020; Nix and Moore 2020). Some patients with Becker muscular dystrophy and in frame deletions of exons 45 to 51 may present deficient nNOS with normal dystrophin antibodies to dystrophin Rod domain (DYS1), Dystrophin carboxy-terminal (DYS2), and Dystrophin amino-terminal (DYS3) (Dubowitz et al. 2020, Nix and Moore 2020). Therefore, for that group of patients, nNOS deficiency may be the only clue to the correct immunohistochemical diagnosis.

Female symptomatic carriers of dystrophinopathy present a mosaic pattern of dystrophin deficiency, ie, with groups of dystrophin positive and negative fibers (Fig. 5), that in most cases are related to inactivation of the mutated $\mathrm{X}$ chromosome in some fibers (Karpati et al. 2010).

The performance of all immunohistochemical reactions simultaneously with normal controls, cut in the same slides, permits the comparison of the intensity of the immunohistochemical reactions between patient and control. The pattern of reaction varies in accordance to the studied protein; it may be on the sarcoplasmic membrane, blood vessels, nuclear membranes or contractile proteins of the sarcoplasm (Fig. 5).

Immunohistochemical reactions may show primary or secondary deficiencies. In primary deficiencies, the deficient antibody reaction demonstrates concordance between the immunophenotypic and genotipic diagnosis. The immunohistochemical deficiency of dysferlin is considered a primary deficiency when a patient presents a pathogenic variant in the dysferlin gene. In this case, the patient receives a definite diagnosis of phenotype and genotype of Limb Girdle Muscular Dystrophy type R2 or LGMD-R2 dysferlin-related (LGMD2B in the old classification) (Straub et al. 2018).

Secondary deficiencies (Table 7) reflect a discordance between immunophenotypic and genotypic diagnosis. Therefore, one must be cautious on immunohistochemical results interpretation, as secondary deficiencies may occur (Table 7, Anderson et al. 2000; Yamamoto et al. 2008; Pénisson-Besnier et al. 2010; Udd et al. 2005; Penttilä et al. 2012; Groen et al. 2007; Müller et al. 2006; Matsuda et al. 2001; Izumi et al. 2015; Barresi 2011).

In order to choose the most appropriate immunohistochemical panel, clinical data are or utmost importance. It is also important to remember, that some muscle dystrophies that occur characteristically in adulthood, may ocasionally, present early onset, such as dysferlinopathy (Paradas et al. 2009), telethoninopathy (Ferreiro et al. 2011), and caveolinopathy (Madrid et al. 2005).

\section{Morphometry in histochemical reactions}

Morphometric analysis may be nowadays performed on digital photographs with micrometric scales using free 
softwares such as Image J (http://imagej.nih.gov/ij) and LibreOffice (https://libreoffice.org) (Table 8).

Congenital fiber type disproportion presents type 1 fiber predominance and almost all type 1 fibers are smaller than type 2 fibers. The exact percentage varies according to the reference: at least 25\% (Dubowitz et al. 2020) or at least 35 to $40 \%$ (Clarke 2011). This latter more strict criteria aims to differentiate between fiber type disproportion that may follow many different congenital myopathies from true cases of fiber type disproportion congenital myopathy (Clarke 2011).

Morphometry is also useful for the evaluation of mitochondrial myopathies using SDH (succinate dehydrogenase) and double COX-SDH (double cytochrome-coxidase followed by succinate dehydrogenase) reactions. The proportion of ragged red equivalent fibers or ragged blue fibers and COX (citochrome c oxidase) negative fibers are used as diagnostic morphological criteria (Table 8) (Bernier et al. 2002).

\section{Electron microscopy}

Transmission electron microscopy is used to evaluate structural muscle components such as sarcolemma, sarcomere, nucleus, mitochondria, and blood vessels. Therefore, electron microscopy is useful for the diagnosis of congenital myopathy (specially recommended for the diagnosis of core myopathies) (North et al. 2014), myofibrillar myopathy, mitochondrial myopathy, and inflammatory myopathy. Among the inflammatory myopathies, electron microscopy is useful to confirm sporadic inclusion body myositis (Fig. 6). Patients with dermatomyositis may present tubulorreticular inclusions inside the cytoplasm of endothelial cells of the capillary blood vessels. These are considered early findings during disease evaluation, that may be found even before the appearance of the inflammatory infiltrate (Fig. 5) (Bronner et al. 2008).

\section{Muscle tissue molecular studies}

Muscle biopsy tissue may be used to perform molecular studies such as Southern blot and western blot.

Southern blot studies are very useful in molecular pathology in order to identify mitochondrial DNA deletions, as in progressive external ophthalmoplegia mitochondriopathy (Bohlega et al. 1996; Shapira and DiMauro 2002). The identification of one single deletion on the mitochondrial DNA, most frequently a 4977 base pair deletion, "common deletion", occurs frequently in sporadic progressive external ophthalmoplegia (Shapira and DiMauro 2002). On the other hand, patients with progressive external ophthalmoplegia with autosomal inheritance may present multiple mitochondrial DNA deletions.
Western blot may be used to quantify the decrease in protein product in patients with muscular dystrophies. The antibodies may include dystrophin, alphadystroglycan, dysferlin, calpain, and telethonin, among others.

In Becker muscular dystrophy, the milder form of dystrophinopathy compared to Duchenne muscular dystrophy, western blot may be helpful to detect only subtle decrease in dystrophin bands.

Western blot studies are very useful for the diagnosis of limb girdle muscular dystrophies. Calpain is an enzyme that presents rapid degradation, that precludes immunohistochemical detection (Groen et al. 2007). Therefore, western blot is very useful for detection of calpain deficiency in limb girdle muscular dystrophy R1 (LGMD-R1 calpain-related). Dysferlin deficiencies may be detected either through western blot or through immunohistochemistry (with Polymer signal amplification). Western blot may also be useful for the detection of anoctamin-5 protein reduction in limb girdle muscular dystrophy R12 (LGMD-R12 anoctamin-related) (Vihola et al. 2018).

Southern blot studies received this name in honor to the last name of the researcher that first detected specific DNA sequences in forensic medicine studies to detected criminal DNA in corporeal fluids. He was able to separate DNA fragments with restriction enzymes that section the DNA and later identify the sequences with labeled nucleic acid complementary probes (Nelson and Cox 2008). Western blot studies are molecular studies used to detect proteins using specific antibodies; this name was an analogy to the Southern blot technique that detects DNA fragments.

\section{Mitochondrial respiratory chain enzymatic activity studies}

Mitochondrial respiratory chain enzymatic studies are very useful to detect mitochondrial complex defects (Barrientos 2002). Combined complex II and complex III defects are indicative of Coenzyme Q10 deficiency and patients may have benefit and clinical improvement with Coenzyme Q10 treatment (Sobreira et al. 1997; Cotta et al. 2020). Either patients with primary coenzyme Q10 deficiency, ie, with biochemical defects in Coenzyme Q10 biosynthesis, as well as patients with secondary coenzyme Q10 deficiency may present clinical improvement with coenzyme Q10 therapy (Trevisson et al. 2011).

\section{Histopathological study of formalin fixed paraffin embedded muscle tissue}

Formalin fixed muscle tissue alone is usually inadequate to confirm a neuromuscular diagnosis. We strongly agree with the World Muscle Society recommended 
standards that liquid nitrogen frozen specimens are necessary for good muscle biopsy diagnosis (Udd et al. 2019).

In our experience, within a group of more than 1500 muscle biopsies evaluated during the last years, paraffin embedded material was useful for diagnosis in less than of the cases with concomitant liquid nitrogen frozen confirmed diagnosis. Therefore, in this group of patients, more than $99 \%$ of paraffin embedded muscle samples resulted in nonspecific or inconclusive results, whereas the liquid nitrogen frozen samples from the same patients were diagnostic.

Special cases in which paraffin embedded material was very useful included inflammatory infiltrate restricted to the fascia and small amyloid deposits. Formalin fixed, paraffin embedded (FFPE) tissue permits the diagnosis of: neurogenic (fascicular) atrophy, the evaluation of the degree of collagen (with a Gomori staining) and fat replacement, in both transverse and longitudinal sections. The analyses of serial sections in the paraffin block is useful for the diagnosis of vasculitis, and other inflammatory conditions, that may present focal or scattered abnormalities in the tissue (Nix and Moore 2020).

\section{Integrated molecular and morphologic myology investigation}

A rationale may be used for ordering either molecular studies or muscle biopsy according to clinical diagnosis (Table 9).

\section{Future perspectives and advanced diagnostic techniques}

Mitochondrial diseases are peculiar. The study of mitochondrial myopathies is very challenging, even for the most experienced myopathologists. Frequently, muscle tissue is the only sample suitable for molecular mitochondrial diagnosis. Therefore molecular studies performed in DNA extracted from blood samples may be inconclusive. These characteristics are related to three long known factors: heteroplasmy, the threshold effect, and mitotic segregation (DiMauro and Schon 2003).

Normal subjects present homoplasmy, characterized by identical normal mitochondriae in all cells. Patients with mitochondriopathies present heteroplasmy, that is and admixture of normal and mutant mitochondrial DNA in different cells and tissues (DiMauro and Schon 2003). The threshold effect is the minimal number of mutant mitochondrial DNA necessary to lead to oxidative dysfunction in a given tissue (DiMauro and Schon 2003). Mitotic segregation is the random distribution of mitochondriae at the time of cell division, resulting in different proportions of mutant mitocondrial DNA in different tissues (DiMauro and Schon 2003).
The omics era for muscle pathology has already begun for patients suspected of mitochondrial myopathies and encephalomyopathies (Rahman and Rahman 2018; Hathazi et al. 2020). Omics technologies are promising technologies that integrate various fields of molecular analysis. They may be gradually incorporated to pathology routine practice during the next years or decades (Karczewski and Snyder 2018; Rahman and Rahman 2018). Omics technologies include: genomics, transcriptomics, proteomics, metabolomics, epigenomics, and interactomics (Rahman and Rahman 2018).

Genomics includes the study of the nuclear and mitochondrial genome including: next generation sequencing (NGS), whole exome sequencing (WES), and whole genome sequencing (WGS) (Rahman and Rahman 2018).

Transcriptomics is the study of RNA, the product of DNA transcription. The RNA whole transcriptome is analyzed using the technique of RNA sequencing (RNAseq) (Rahman and Rahman 2018). This technique allows the identification of deep intronic variants affecting splicing (Rahman and Rahman 2018). Sometimes, RNA sequencing may be helpful to understand the consequences of DNA variants detected through WGS (Rahman and Rahman 2018). This technique was crucial for the discovery of the serum metabolic marker growth differentiation factor-15 (GDF-15) (Kalko et al. 2014). GDF-15 and fibroblast growth factor-21 (FGF-21) are useful serum metabolic markers for the diagnostic investigation of mitochondrial disorders (Scholle et al. 2018; Lehtonen et al. 2020; Hathazi et al. 2020).

Proteomics includes the quantitative study of proteins using mass spectrometry. This technique allows the study of the entire mitochondrial ribosome and the post-translational modifications such as lysine acetylation, malonylation, and succinylation (Rahman and Rahman 2018, Hathazi et al. 2020).

Metabolomics is a spectrometry-based technique. The metabolome technique enables to profile thousands of molecules. It allows the identification of products of oxidative stress, redox imbalance, and energy deficiency (Rahman and Rahman 2018).

Epigenomics includes the study of reversible alterations in DNA expression that do not modify the DNA sequence such as the downstream regulation of the Tricarboxylic acid cycle (Krebs cycle) induced by metabolites and enzymes (Rahman and Rahman 2018).

Interactomics or integrated omics is the combined interpretation of data from transcriptomics, proteomics, and metabolomics. It may be useful to reveal the physiopathological pathways for mitochondrial cristae organization, endoplasmic reticulum-mitochondrial communication, and mitochondrial dynamics (mitochondrial motility within the cell) (Rahman and Rahman 2018, Hathazi et al. 2020). 


\section{Conclusions}

In ideal situations, the choice of the muscle to be submitted to biopsy involves an integrated multiprofessional approach to provide appropriate patient care. Liquid nitrogen specimens are necessary for effective muscle biopsy diagnosis.

The choice of the special techniques and types of exams should be individualized for each patient, according to the clinical presentation, symptoms evolution, familial history, physical and neurological exam, laboratorial, neurophysiological, and imaging studies.

The interpretation of muscle abnormalities should be performed together with clinical information in order to avoid erroneous interpretation of morphological findings.

Muscle biopsy is useful for the differential diagnosis of immune mediated myopathies, muscular dystrophies, congenital myopathies, and mitochondrial myopathies. With the advent of new molecular studies, muscle biopsy has been necessary to confirm the pathogenicity of new gene variants. In doubtful cases, muscle biopsy may provide the morphologic phenotype necessary for diagnostic confirmation. Due to organ specific mutation load in mitochondriopathies, the muscle tissue may be the only source of representative DNA or RNA samples for molecular diagnosis.

\footnotetext{
Abbreviations

A: Aggregates; ABN: Brazilian Academy of Neurology [Academia Brasileira de Neurologia]; Alpha-dystroglycan (VIA4, IIH6C4): Alpha-dystroglycan antibody clones VIA4 and IIH6C4; BL: B lymphocyte; C: Capillary vessel wall; CD8: Cluster of differentiation 8T Iymphocyte; Complex II: Complex two of the Mitochondrial Respiratory Chain; Complex III: Complex three of the Mitochondrial Respiratory Chain; COX: Cytochrome c oxidase; COXSDH: Double cytochrome-c-oxidase followed by succinate dehydrogenase reaction; DM1: Myotonic dystrophy type 1 (Steinert's myotonic dystrophy); DNA: Deoxyribonucleic acid; DYS1: Dystrophin - Rod domain; DYS2: Dystrophin - carboxy-terminal; DYS3: Dystrophin - amino terminal; EM: Extracellular matrix; HE: Hematoxylin and eosin; FGF-21: Fibroblast growth factor-21; FSHD: Facioscapulohumeral muscular dystrophy; GDF15: Growth differentiation factor-15; hIBM: Hereditary inclusion body myopathy; IBMPFD: Hereditary inclusion body myopathy with Paget's disease of bone and frontotemporal dementia; L: Lymphocyte; LGMD: Limb Girdle Muscular Dystrophy; LGMD-R1 calpain-related: Limb Girdle Muscular Dystrophy recessive type 1 related to the calpain gene; LGMD-R2 dysferlinrelated: Limb Girdle Muscular Dystrophy recessive type 2 related to the dysferlin gene; LGMD-R3 alpha sarcoglycan-related: Limb Girdle Muscular Dystrophy recessive type 3 related to the alpha-sarcoglycan gene; LGMD-R4 beta sarcoglycan-related: Limb Girdle Muscular Dystrophy recessive type 4 related to the beta-sarcoglycan gene; LGMD-R5 gamma sarcoglycanrelated: Limb Girdle Muscular Dystrophy recessive type 5 related to the gamma-sarcoglycan gene; LGMD-R6 delta sarcoglycan-related: Limb Girdle Muscular Dystrophy recessive type 6 related to the delta-sarcoglycan gene; LGMD-R7 telethonin-related: Limb Girdle Muscular Dystrophy recessive type 7 related to the telethonin gene; LGMD-R9 FKRP-related: Limb Girdle Muscular Dystrophy recessive type 9 related to the FKRP gene; LGMD-R10 titin related: Limb Girdle Muscular Dystrophy recessive type 10 related to the titin gene; LGMD-R12 anoctamin-5 related: Limb Girdle Muscular Dystrophy recessive type 12 related to anoctamin-5 gene; LGMD-D1 DNAJB6related: Limb Girdle Muscular Dystrophy dominant type 1 related to the DNAJB6 gene; LGMD-D2 TNPO3-related: Limb Girdle Muscular Dystrophy dominant type 2 related to the TNPO3 gene; Mac: Macrophage; MHC-I: Major histocompatibility complex class I; MRI: Magnetic resonance imaging; MRC: Medical Research Council; NADH: Nicotinamide adenine dinucleotide;
}

NGS: Next Generation Sequencing; NM: Nuclear membrane; PAS: Periodic acid Schiff; P: Plasma cell; RF: Regeneration fiber; S: Sarcoplasm;

SDH: Succinate dehydrogenase; sIBM: Sporadic inclusion body myositis; SM: Sarcoplasmic membrane; SMA: Spinal Muscular Atrophy; TL: T lymphocyte; TL/BL: T and B lymphocytes; Type 1D: Mean type 1 fiber diameter; Type 2D: Mean type 2 fiber diameter; VCPDM: Vocal cord and pharyngeal weakness with distal myopathy; WES: Whole Exome Sequencing; WGS: Whole Genome Sequencing

\section{Acknowledgments}

We would like to thank Cleides Campos de Oliveira and Simone Ferreira Inacio for technical assistance. We thank Dr. Isabel Cristina Soares Brandão for the critical review of the first draft of the manuscript.

\section{Authors' contributions}

AC was responsible for the conception, design, organization, photographic documentation, draft, and revision of the final version of the manuscript. EC and JV contributed with neurophysiological data. ALdCJ contributed with muscle imaging data. SBJ contributed with mitochondrial respiratory chain studies. MMN, AFC, MMM, SVN, RXN, APV contributed with clinical data. EBS, MIL, BAC contributed with electron microscopy information. AC and JFP were responsible for muscle biopsy analyses. The author(s) read and approved the final manuscript.

\section{Funding}

Not applicable.

\section{Availability of data and materials Not applicable.}

\section{Ethics approval and consent to participate}

This manuscript has been approved by the Ethics and Research Comittee of The SARAH Network of Rehabilitation Hospitals and "Plataforma Brasil", number 1.703.918. CAAE: 58086316.6.0000.0022.

\section{Consent for publication}

A consent for publication was not necessary as no individual data from patients were used.

\section{Competing interests}

The authors declare that they have no competing interests.

\section{Author details}

${ }^{1}$ Department of Pathology, The SARAH Network of Rehabilitation Hospitals, Av. Amazonas, 5953 Gameleira, Belo Horizonte, MG 30510-000, Brazil. 2Department of Neurophysiology, The SARAH Network of Rehabilitation Hospitals, Belo Horizonte, MG, Brazil. ${ }^{3}$ Department of Radiology, The SARAH Network of Rehabilitation Hospitals, Belo Horizonte, MG, Brazil. ${ }^{4}$ Department of Pediatrics, The SARAH Network of Rehabilitation Hospitals, Belo Horizonte, MG, Brazil. ${ }^{5}$ Department of Electron Microscopy, The SARAH Network of Rehabilitation Hospitals, Brasília, DF, Brazil. ${ }^{6}$ Department of Surgery, The SARAH Network of Rehabilitation Hospitals, Belo Horizonte, MG, Brazil. ${ }^{7}$ Department of Neurology, The SARAH Network of Rehabilitation Hospitals, Belo Horizonte, MG, Brazil.

Received: 29 October 2020 Accepted: 21 December 2020

Published online: 14 January 2021

\section{References}

Amato AA, Russell JA (2008) Neuromuscular disorders. McGrawHill Medical, New York. Printed in China, pp 1-775

Anderson JR (1985) Atlas of skeletal muscle pathology. In: Current histopathology, vol 9. MTP Press Limited, Kluwer Academic Publishers Group, Lancaster, pp 1-168

Anderson LV, Harrison RM, Pogue R, Vafiadaki E, Pollitt C, Davison K et al (2000) Secondary reduction in calpain 3 expression in patients with limb girdle muscular dystrophy type 2B and Miyoshi myopathy (primary dysferlinopathies). Neuromuscul Disord 10:553

Barresi R (2011) From proteins to genes: immunoanalysis in the diagnosis of muscular dystrophies. Skelet Muscle 1:24 
Barrientos A (2002) In vivo and in organello assessment of OXPHOS activities. Methods. 26:307

Benarroch L, Bonne G, Rivier F, Hamroun D (2019) The 2020 version of the gene table of neuromuscular disorders (nuclear genome). Neuromuscul Disord 29: 980

Bernier FP, Boneh A, Dennett X, Chow CW, Cleary MA, Thorburn DR (2002) Diagnostic criteria for respiratory chain disorders in adults and children. Neurology. 59:1406

Bohlega S, Tanji K, Santorelli FM, Hirano M, al-Jishi A, DiMauro S (1996) Multiple mitochondrial DNA deletions associated with autosomal recessive ophthalmoplegia and severe cardiomyopathy. Neurology 46:1329

Bronner IM, Hoogendijk JE, Veldman H, Ramkema M, van den Bergh Weerman MA, Rozemuller AJ et al (2008) Tubuloreticular structures in different types of myositis: implications for pathogenesis. Ultrastruct Pathol 32:123

Clarke NF (2011) Congenital fiber-type disproportion. Semin Pediatr Neurol 18: 264

Cotta A, Alston CL, Baptista-Junior S, Paim JF, Carvalho E, Navarro MM et al (2020) Early-onset coenzyme Q10 deficiency associated with ataxia and respiratory chain dysfunction due to novel pathogenic COQ8A variants, including a large intragenic deletion. JIMD Rep 54:45

Cotta A, Carvalho E, da-Cunha-Junior AL (2019) [Capítulo 92. Distrofias Musculares Cintura-Membros] Chapter 92. Limb-girdle muscular dystrophy. In: Gagliardi RJ, Takayanagui OM (eds) [Tratado de Neurologia da Academia Brasileira de

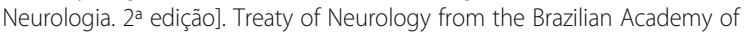
Neurology, 2nd edn. Elsevier, pp 587-599

Cotta A, Carvalho E, da-Cunha-Junior AL, Paim JF, Navarro MM, Valicek J et al (2014a) Common recessive limb girdle muscular dystrophies differential diagnosis: why and how? Arq Neuropsiquiatr 72:721

Cotta A, Paim JF (2016) Muscle biopsy reporting. Arch Pathol Lab Med 140:879

Cotta A, Paim JF, Carvalho E, da-Cunha-Junior AL, Navarro MM, Valicek J et al (2017) The relative frequency of common neuromuscular diagnoses in a reference center. Arq Neuropsiquiatr $75: 789$

Cotta A, Paim JF, da-Cunha-Junior AL, Neto RX, Nunes SV, Navarro MM et al (2014b) Limb-girdle muscular dystrophy type $2 \mathrm{G}$ with myopathic-neurogenic motor unit potentials and a novel muscle image pattern. BMC Clin Pathol 14:41

da Silva HC, dos Santos Almeida C, Brandão JC, Nogueira e Silva CA, de Lorenzo ME et al (2013) Malignant hyperthermia in Brazil: analysis of hotline activity in 2009. Braz J Anesthesiol 63:13

Dastgir J, Rutkowski A, Alvarez R, Cossette SA, Yan K, Hoffmann RG et al (2016) Common data elements for muscle biopsy reporting. Arch Pathol Lab Med 140:51

de Visser M, Bakker E, Defesche JC, Bolhuis PA, van Ommen GJ (1990) An unusual variant of Becker muscular dystrophy. Ann Neurol 27:578

DiMauro S, Schon EA (2003) Mitochondrial respiratory-chain diseases. N Engl J Med 348:2656

Dubowitz V, Brooke M (1973) Muscle biopsy: a modern approach. W.B. Saunders Company. Ltd. Lavernham Press Ltd., Suffolk, pp 1-475

Dubowitz V, Sewry C (2007) Muscle biopsy. A practical approach, 3rd edn. Saunders Elsevier, pp 1-611 https://www.elsevier.com/books/muscle-biopsya-practicalapproach/dubowitz/978-1-4160-2593-1

Dubowitz V, Sewry CA, Oldfors A (2013) Muscle biopsy: a practical approach, 4th edn. Saunders Elsevier, Printed in China, pp 1-552 https://www.elsevier.com/ books/muscle-biopsy-a-practical-approach/dubowitz/978-0-7020-4340-6

Dubowitz V, Sewry CA, Oldfors A (2020) Muscle biopsy: a practical approach, 5th edn. Saunders Elsevier, Printed in China, pp 1-600 https://www.elsevier.com/ books/muscle-biopsy/dubowitz/978-0-7020-7471-4

Dubowiz V (1995) Muscle disorders in childhood, 2nd edn. W.B. Saunders Company Ltd, London Printed in Bath, England, pp 1-540

Engel AG, Franzini-Armstrong C (2004) Myology, 3rd edn. McGraw-Hill, Medical Publishing Division, New York, pp 1-1960

Fang W, Huang CC, Chu NS, Chen CJ, Lu CS, Wang CC (1997) Childhood-onset autosomal-dominant limb-girdle muscular dystrophy with cardiac conduction block. Muscle Nerve 20:286

Fardeau M (2017) [Sur la technique des biopsies musculaires (IV) L'avènement de I'histochimie et de la cytoenzymologie dans l'analyse des biopsies musculaires Un bref et personnel survol historique.] About the technique of muscle biopsy (IV). The advent of histochemistry and cytoenzymology in the analysis of muscle biopsies. A short and personal historical overview. Med Sci 33:7

Ferreiro A, Mezmezian M, Olivé M, Herlicoviez D, Fardeau M, Richard P et al (2011) Telethonin-deficiency initially presenting as a congenital muscular dystrophy. Neuromuscul Disord 21:433
Gamez J, Navarro C, Andreu AL, Fernandez JM, Palenzuela L, Tejeira S et al (2001) Autosomal dominant limb-girdle muscular dystrophy: a large kindred with evidence for anticipation. Neurology 56:450

Greenberg SA (2019) Inclusion body myositis: clinical features and pathogenesis. Nat Rev Rheumatol 15:257

Groen EJ, Charlton R, Barresi R, Anderson LV, Eagle M, Hudson J et al (2007) Analysis of the UK diagnostic strategy for limb girdle muscular dystrophy 2A. Brain. 130:3237

Hackman P, Sandell S, Sarparanta J, Luque H, Huovinen S, Palmio J et al (2011) Four new Finnish families with LGMD1D; refinement of the clinical phenotype and the linked 7q36 locus. Neuromuscul Disord 21:338

Harms MB, Sommerville RB, Allred P, Bell S, Ma D, Cooper P et al (2012) Exome sequencing reveals DNAJB6 mutations in dominantly-inherited myopathy. Ann Neurol 71:407

Hathazi D, Griffin H, Jennings MJ, Giunta M, Powell C, Pearce SF et al (2020) Metabolic shift underlies recovery in reversible infantile respiratory chain deficiency. EMBO J 39:e105364

Hicks D, Sarkozy A, Muelas N, Koehler K, Huebner A, Hudson G et al (2011) A founder mutation in Anoctamin 5 is a major cause of limb-girdle muscular dystrophy. Brain 134:171

Izumi R, Niihori T, Takahashi T, Suzuki N, Tateyama M, Watanabe C et al (2015) Genetic profile for suspected dysferlinopathy identified by targeted nextgeneration sequencing. Neurol Genet 1:e36

Kalko SG, Paco S, Jou C, Rodríguez MA, Meznaric M, Rogac M et al (2014) Transcriptomic profiling of TK2 deficient human skeletal muscle suggests a role for the p53 signalling pathway and identifies growth and differentiation factor-15 as a potential novel biomarker for mitochondrial myopathies. BMC Genomics 15:91

Kaneko K, Aoki M (2014) A novel mutation in PNPLA2 causes neutral lipid storage disease with myopathy and triglyceride deposit cardiomyovasculopathy: a case report and literature review. Neuromuscul Disord 24:634

Karczewski KJ, Snyder MP (2018) Integrative omics for health and disease. Nat Rev Genet 19:299

Karpati G, Hilton-Jones D, Bushby K, Griggs RC (2010) Disorders of voluntary muscle, 10th edn. Cambridge University Press, Cambridge, pp 1-520

Layzer R, Lee HS, Iverson D, Margeta M (2009) Dermatomyositis with inclusion body myositis pathology. Muscle Nerve 40:469

Lefter S, Hardiman O, McLaughlin RL, Murphy SM, Farrell M, Ryan AM (2015) A novel MYH7 Leu1453pro mutation resulting in Laing distal myopathy in an Irisch family. Neuromuscul Disord 25:155

Lehtonen JM, Auranen M, Darin N, Sofou K, Bindoff L, Hikmat O et al (2020) Diagnostic value of serum biomarkers FGF21 and GDF15 compared to muscle sample in mitochondrial disease. J Inherit Metab Dis https://doi.org/ 10.1002/jimd.12307 Online ahead of print

Levy JA (1978) Miopatias, 1st edn. Livraria Atheneu, Rio de Janeiro, pp 1-271

Loughlin M (1993) Muscle biopsy: a laboratory investigation. Butterworth Heinemann Ltd, Oxford, pp 1-242

Madrid RE, Kubisch C, Hays AP (2005) Early-onset toe walking in rippling muscle disease due to a new caveolin-3 gene mutation. Neurology. 65:1301

Malfatti E, Romero NB (2017) Diseases of the skeletal muscle. Handb Clin Neurol 145:429

Matsuda C, Hayashi YK, Ogawa M, Aoki M, Murayama K, Nishino I et al (2001) The sarcolemmal proteins dysferlin and caveolin-3 interact in skeletal muscle. Hum Mol Genet 10:1761

Moline SW, Glenner GG (1964) Ultrarapid tissue freezing in liquid nitrogen. J Histochem Cytochem 12:777

Moreira ES, Vainzof M, Marie SK, Sertié AL, Zatz M, Passos-Bueno MR (1997) The seventh form of autosomal recessive limb-girdle muscular dystrophy is mapped to 17q11-12. Am J Hum Genet 61:151

Müller JS, Piko H, Schoser BG, Schlotter-Weigel B, Reilich P, Güster S et al (2006) Novel splice site mutation in the caveolin-3 gene leading to autosomal recessive limb girdle muscular dystrophy. Neuromuscul Disord 16:432

Narayanaswami P, Weiss M, Selcen D, David W, Raynor E, Carter G et al (2014) Evidence-based guideline summary: diagnosis and treatment of limb-girdle and distal dystrophies: report of the guideline development subcommittee of the American Academy of Neurology and the practice issues review panel of the American Association of Neuromuscular \& Electrodiagnostic Medicine. Neurology 83:1453

Negrão L, Matos A, Geraldo A, Rebelo O (2010) Limb-girdle muscular dystrophy in a Portuguese patient caused by a mutation in the telethonin gene. Acta Myol 29:21 
Nelson DL, Cox MM (2008) Lehninger principles of biochemistry, 5th edn. WH Freeman and Company, New York, pp 1-1158

Nishino I, Carrillo-Carrasco N, Argov Z (2015) GNE myopathy: current update and future therapy. J Neurol Neurosurg Psychiatry 86:385

Nix JS, Moore SA (2020) What every neuropathologist needs to know: the muscle biopsy. J Neuropathol Exp Neurol 79:719

North KN, Wang CH, Clarke N, Jungbluth H, Vainzof M, Dowling JJ et al (2014) Approach to the diagnosis of congenital myopathies. Neuromuscul Disord 24:97

O'Connell FP, Pinkus JL, Pinkus GS (2004) CD138 (syndecan-1), a plasma cell marker immunohistochemical profile in hematopoietic and nonhematopoietic neoplasms. Am J Clin Pathol 121:254

Oldfors A (2007) Hereditary myosin myopathies. Neuromuscul Disord 17:355

Paim JF, Cotta A, Vargas AP, Navarro MM, Valicek J, Carvalho E et al (2013) Muscle phenotypic variability in limb girdle muscular dystrophy 2G. J Mol Neurosci 50:339

Palmio J, Evilä A, Bashir A, Norwood F, Viitaniemi K, Vihola A et al (2016) Reevaluation of the phenotype caused by the common MATR3 p.Ser85Cys mutation in a new family. J Neurol Neurosurg Psychiatry 87:448

Paradas C, González-Quereda L, De Luna N, Gallardo E, García-Consuegra I, Gómez H et al (2009) A new phenotype of dysferlinopathy with congenital onset. Neuromuscul Disord 19:21

Paradas C, Márquez C, Gallardo E, De Luna N, Chinchón I, Recan D et al (2005) Xlinked Emery-Dreifuss muscular dystrophy and vacuoles: an immunohistochemical characterization. Muscle Nerve 32:61

Pasnoor M, Dimachkie MM (2019) Approach to Muscle and Neuromuscular Junction Disorders. Continuum (Minneap Minn) 25:1536. https://doi.org/10. 1212/CON.0000000000000799

Pénisson-Besnier I, Hackman P, Suominen T, Sarparanta J, Huovinen S, RichardCrémieux I et al (2010) Myopathies caused by homozygous titin mutations: limb-girdle muscular dystrophy $2 \mathrm{~J}$ and variations of phenotype. J Neurol Neurosurg Psychiatry 81:1200

Pénisson-Besnier I, Talvinen K, Dumez C, Vihola A, Dubas F, Fardeau M et al (2006) Myotilinopathy in a family with late onset myopathy. Neuromuscul Disord 16:427

Penttilä S, Palmio J, Suominen T, Raheem O, Evilä A, Muelas Gomes N et al (2012) Eight new mutations and the expanding phenotype variability in muscular dystrophy caused by ANO5. Neurology 78:897

Rahman J, Rahman S (2018) Mitochondrial medicine in the omics era. Lancet. 391:2560

Rajakulendran S, Parton M, Holton JL, Hanna MG (2011) Clinical and pathological heterogeneity in late-onset partial merosin deficiency. Muscle Nerve 44:590

Reilich P, Schramm N, Schoser B, Schneiderat P, Strigl-Pill N, Müller-Höcker J et al (2010) Facioscapulohumeral muscular dystrophy presenting with unusual phenotypes and atypical morphological features of vacuolar myopathy. J Neurol 257:1108

Rose MR, ENMC IBM Working Group (2013) 188th ENMC International Workshop: inclusion body myositis, 2-4 December 2011, Naarden, The Netherlands. Neuromuscul Disord 23:1044

Scholle LM, Lehmann D, Deschauer M, Kraya T, Zierz S (2018) FGF-21 as a potential biomarker for mitochondrial diseases. Curr Med Chem 25:2070

Scola RH, Pereira ER, Lorenzoni PJ, Werneck LC (2007) Toxic myopathies: muscle biopsy features. Arq Neuropsiquiatr 65:82

Shapira AH, DiMauro S (2002) Practical neurology. In: Mitochondrial disorders in neurology, vol 2. Butterworth Heinemann, Boston, pp 1-304

So PC (1985) An easy way to orientate small muscle biopsy tissue. J Clin Pathol 38:1312

Sobreira C, Hirano M, Shanske S, Keller RK, Haller RG, Davidson E et al (1997) Mitochondrial encephalomyopathy with coenzyme Q10 deficiency. Neurology. 48:1238

Straub V, Murphy A, Udd B, LGMD workshop study group (2018) 229th ENMC international workshop: Limb girdle muscular dystrophies - Nomenclature and reformed classification Naarden, the Netherlands, 17-19 March 2017. Neuromuscul Disord 28:702

Trevisson E, DiMauro S, Navas P, Salviati L (2011) Coenzyme Q deficiency in muscle. Curr Opin Neurol 24:449

Udd B (2012) Distal myopathies - new genetic entities expand diagnostic challenge. Neuromuscul Disord 22:5

Udd B, Stenzel W, Oldfors A, Olivé M, Romero N, Lammens M et al (2019) 1st ENMC European meeting: the EURO-NMD pathology working group recommended standards for muscle pathology Amsterdam, The Netherlands, 7 December 2018. Neuromuscul Disord 29:483

Udd B, Vihola A, Sarparanta J, Richard I, Hackman P (2005) Titinopathies and extension of the M-line mutation phenotype beyond distal myopathy and LGMD2J. Neurology. 64:636

Van De Vlekkert J, Maas M, Hoogendijk JE, De Visser M, Van Schaik IN (2015) Combining MRI and muscle biopsy improves diagnostic accuracy in subacute-onset idiopathic inflammatory myopathy. Muscle Nerve 51:253

Vihola A, Luque H, Savarese M, Penttilä S, Lindfors M, Leturcq F et al (2018) Diagnostic anoctamin-5 protein defect in patients with ANO5-mutated muscular dystrophy. Neuropathol Appl Neurobiol 44:441

Waddell LB, Tran J, Zheng XF, Bönnemann CG, Hu Y, Evesson FJ et al (2011) A study of FHL1, BAG3, MATR3, PTRF and TCAP in Australian muscular dystrophy patients. Neuromuscul Disord 21:776

Werneck LC, Silvado CE (1981) "Central core" myopathy: report of a case. Arq Neuropsiquiatr 39:230

Yamamoto LU, Velloso FJ, Lima BL, Fogaça LL, de Paula F, Vieira NM et al (2008) Muscle protein alterations in LGMD2I patients with different mutations in the Fukutin-related protein gene. J Histochem Cytochem 56:995

\section{Publisher's Note}

Springer Nature remains neutral with regard to jurisdictional claims in published maps and institutional affiliations.

Ready to submit your research? Choose BMC and benefit from

- fast, convenient online submission

- thorough peer review by experienced researchers in your field

- rapid publication on acceptance

- support for research data, including large and complex data types

- gold Open Access which fosters wider collaboration and increased citations

- maximum visibility for your research: over $100 \mathrm{M}$ website views per year

At BMC, research is always in progress.

Learn more biomedcentral.com/submissions 